\title{
Poly(Asymmetrical Glycolide)s: The Mechanisms and Thermosensitive Properties
}

Duygu Çetin, ${ }^{1}$ Mehmet Onur Arıcan, ${ }^{2}$ Halime Kenar, ${ }^{2,3}$ Serap Mert, ${ }^{2,4,5}$ Olcay Mert ${ }^{1,2 *}$

${ }^{1}$ Department of Chemistry, Kocaeli University, 41001, Kocaeli, Turkey

${ }^{2}$ Department of Polymer Science and Technology, Kocaeli University, 41001, Kocaeli, Turkey

${ }^{3}$ Experimental and Clinical Research Center, Kocaeli University, 41001, Kocaeli, Turkey

${ }^{4}$ Center for Stem Cell and Gene Therapies Research and Practice, Kocaeli University, Kocaeli, 41001, Turkey

${ }^{5}$ Department of Chemistry \& Chemical Processing Tech., Kocaeli University, Kocaeli, 41140, Turkey 


\section{ATR-FTIR Spectra}

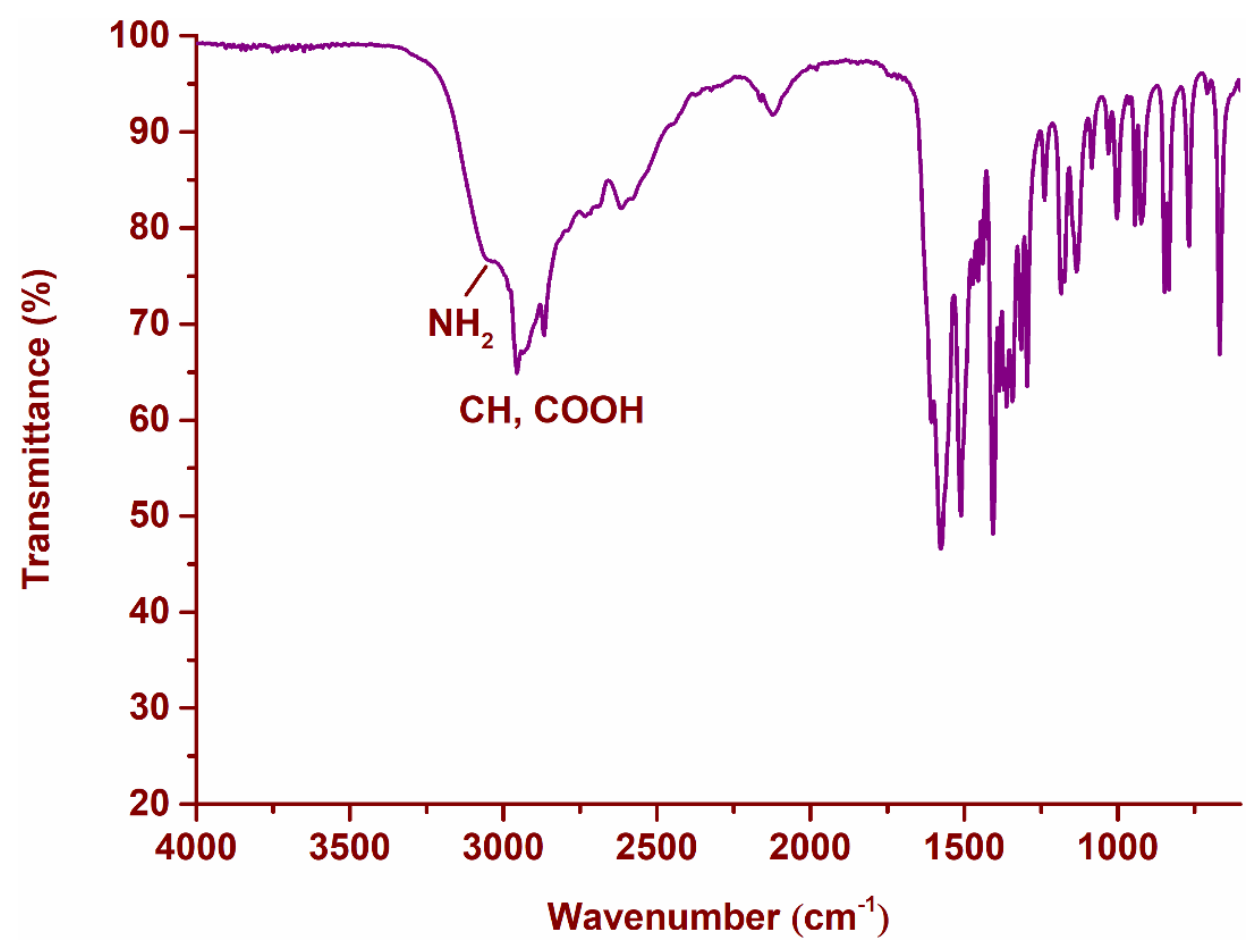

Figure S1. ATR-FTIR spectrum of L-Leucine (1).

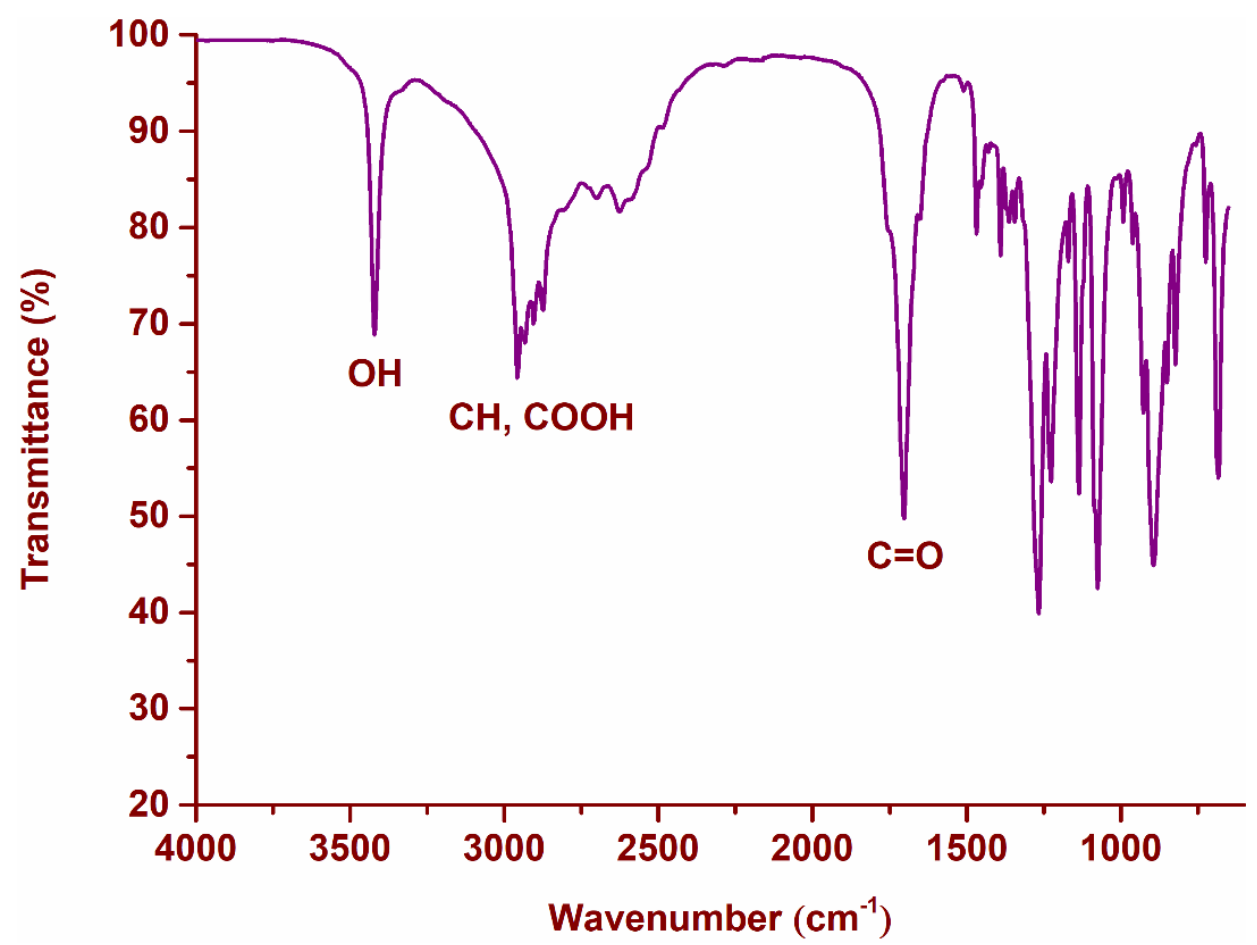

Figure S2. ATR-FTIR spectrum of (S)-2-hydroxy-4-methylpentanoic acid (2). 


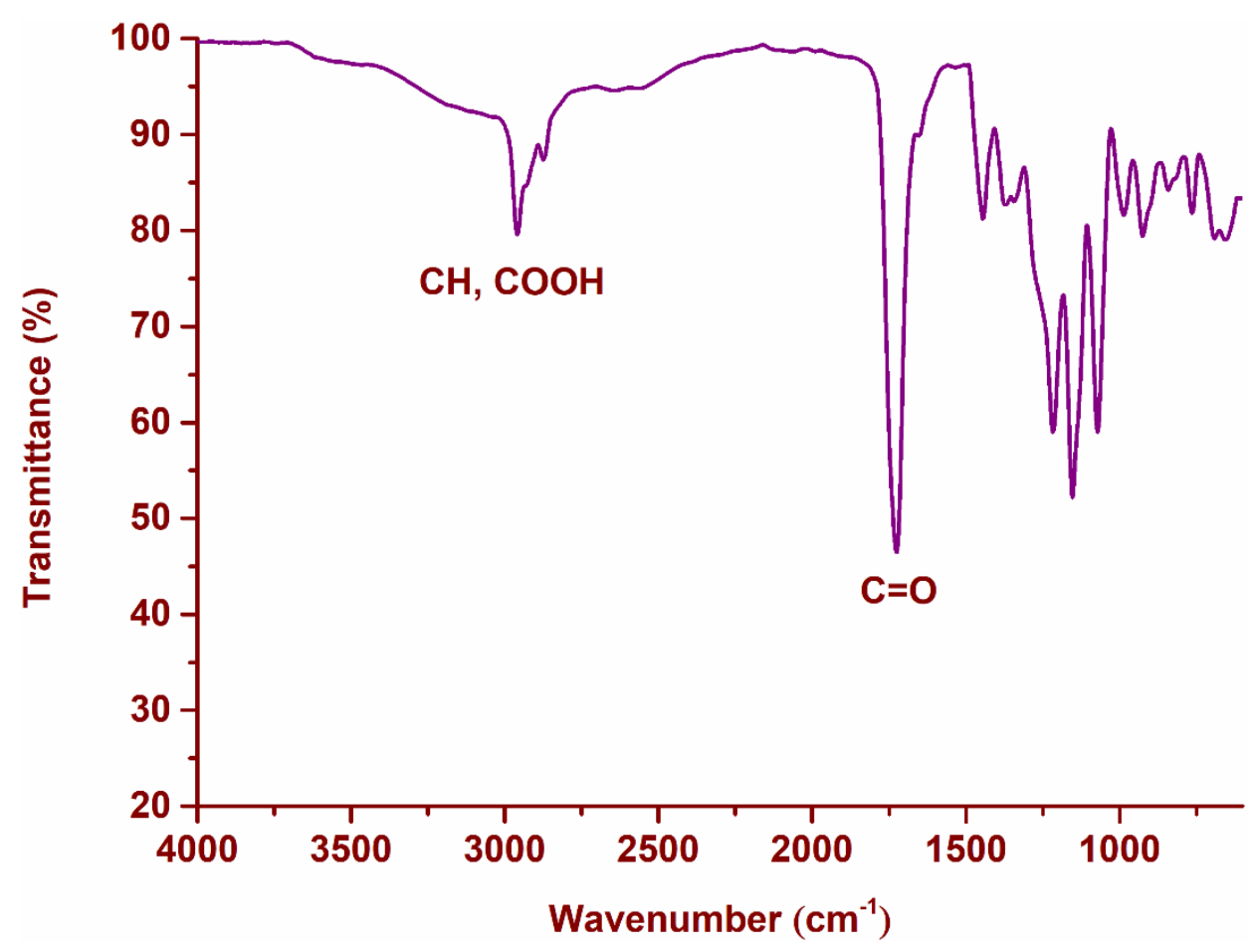

Figure S3. ATR-FTIR spectrum of 2-((2-bromopropanoyl)oxy)-4methylpentanoic acid (3).

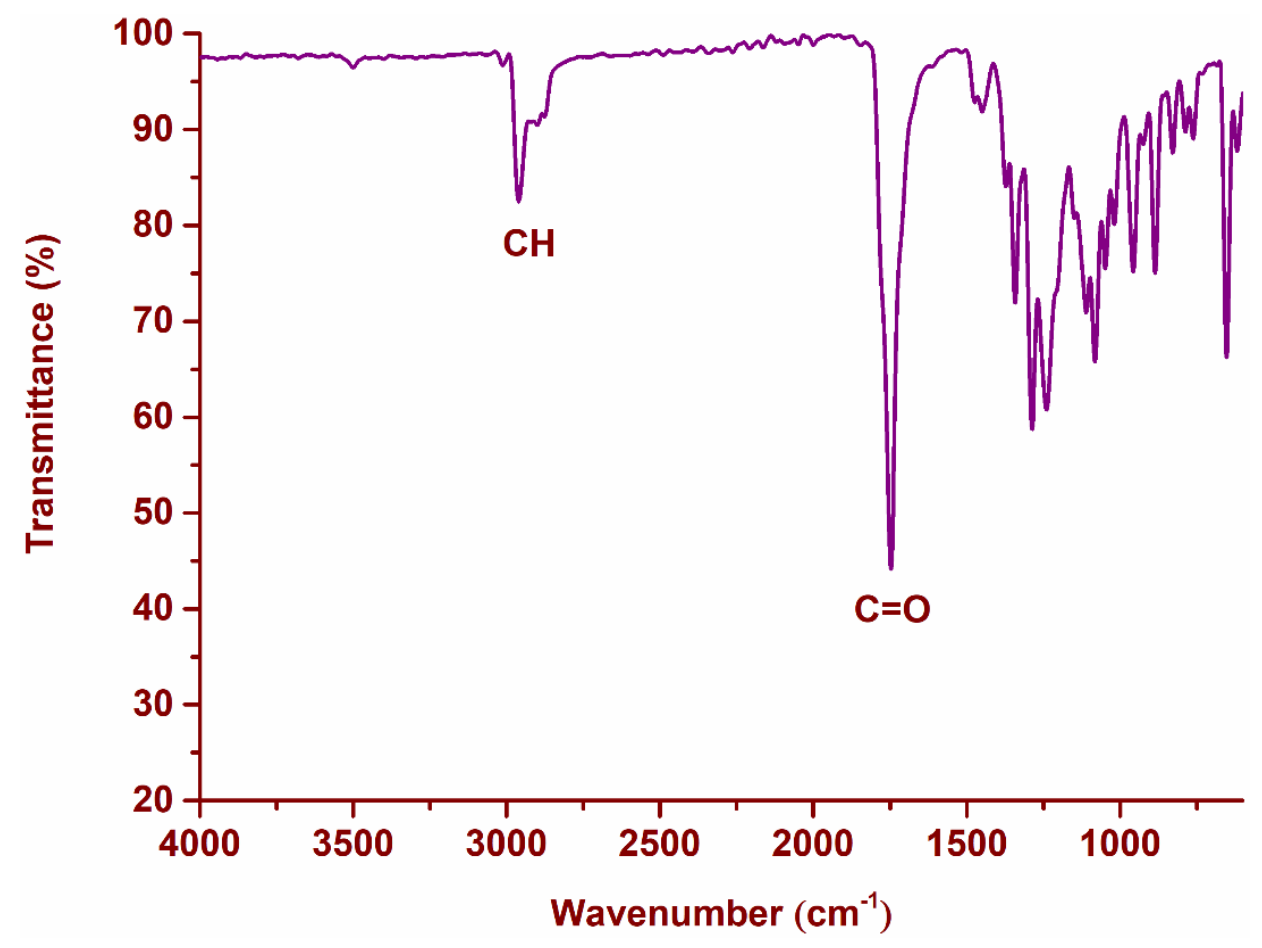

Figure S4. ATR-FTIR spectrum of (3S,6S)-3-isobutyl-6-methyl-1,4dioxane-2,5-dione (isobutyl lactide, IBL) (4). 


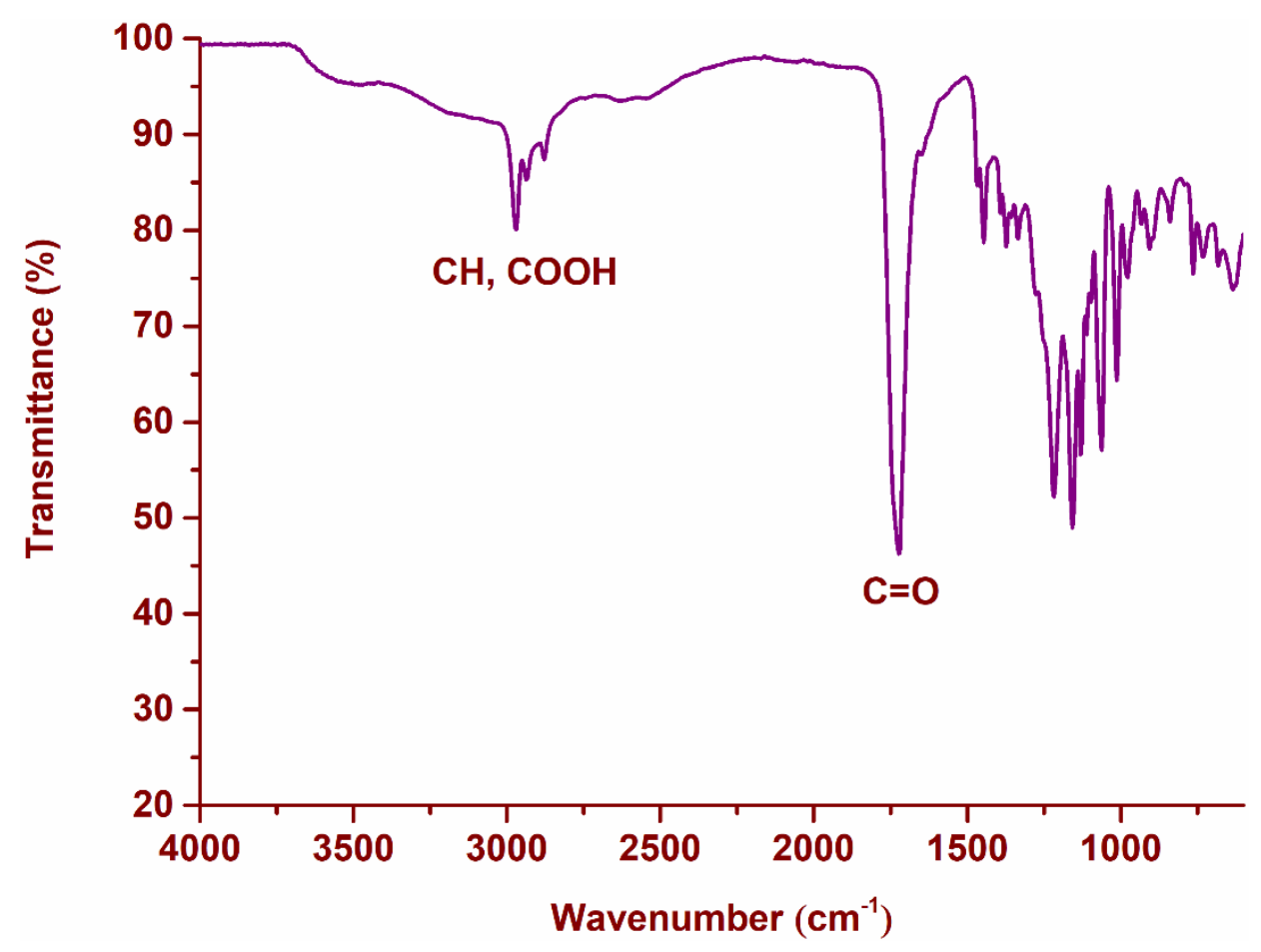

Figure S5. ATR-FTIR spectrum of 2-((2-bromopropanoyl)oxy)-3methylbutanoic acid.

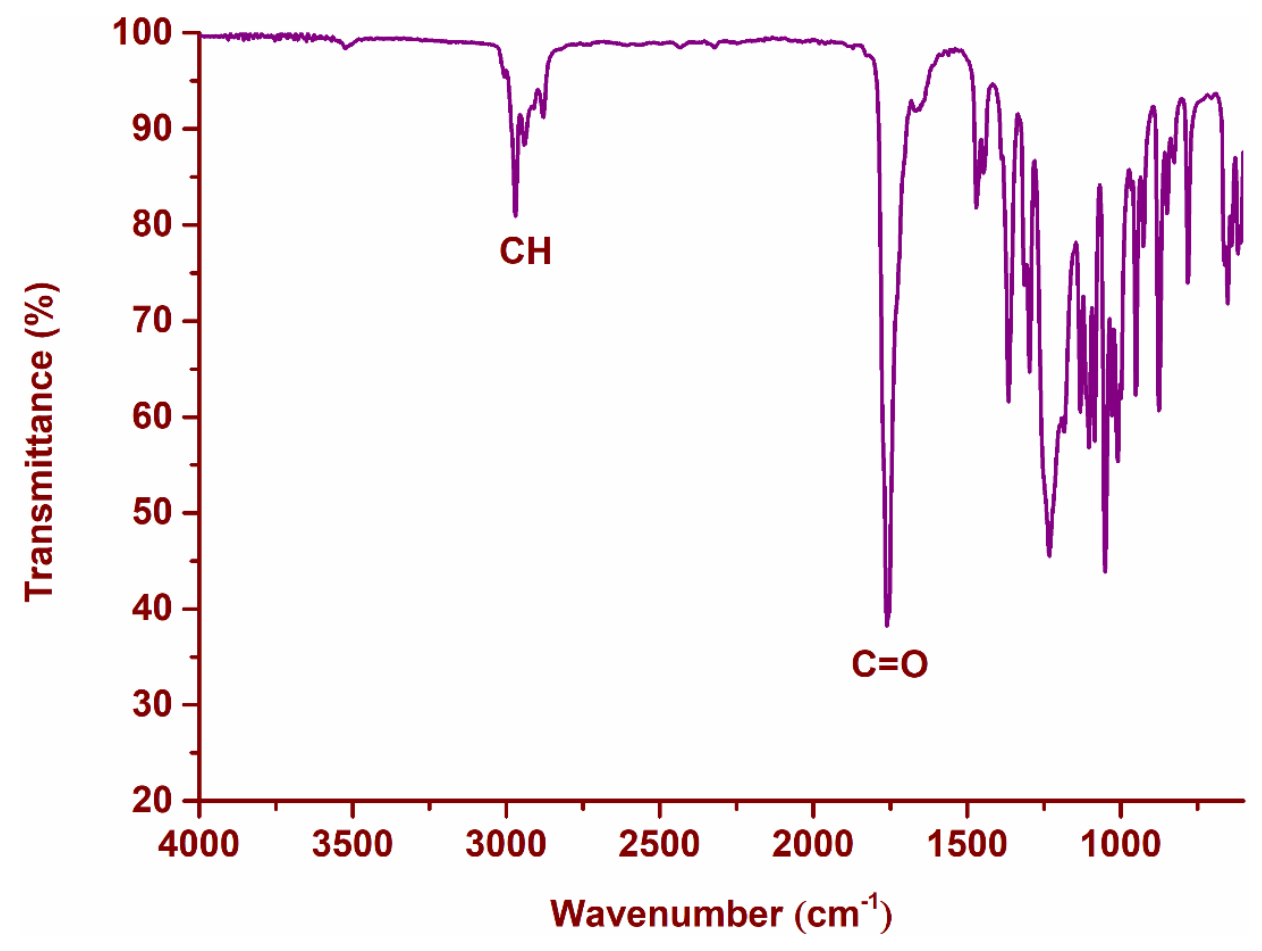

Figure S6. ATR-FTIR spectrum of 3-isopropyl-6-methyl-1,4-dioxane-2,5dione (isopropyl lactide, IPL). 


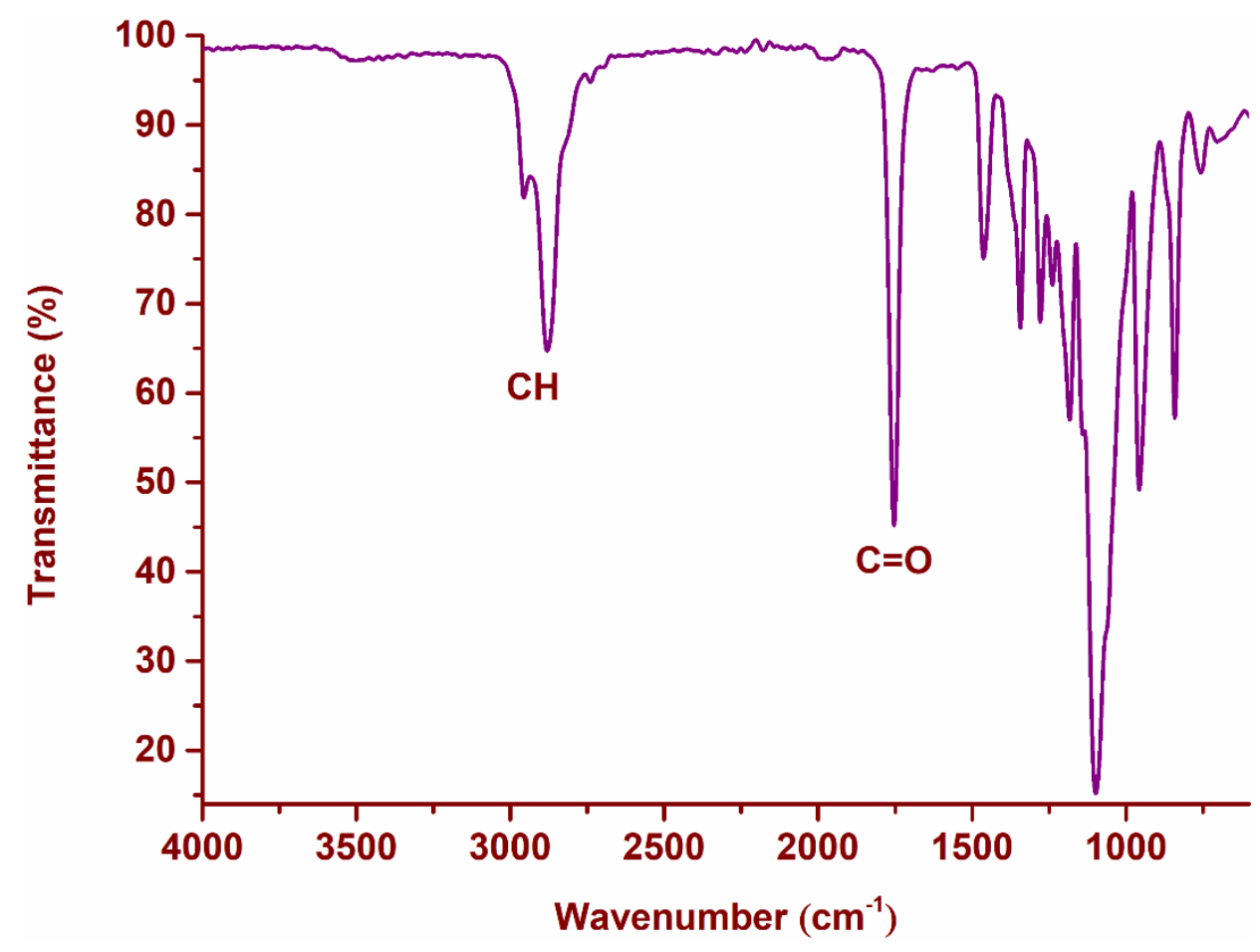

Figure S7. ATR-FTIR spectrum of MePEG-PIBL 7.

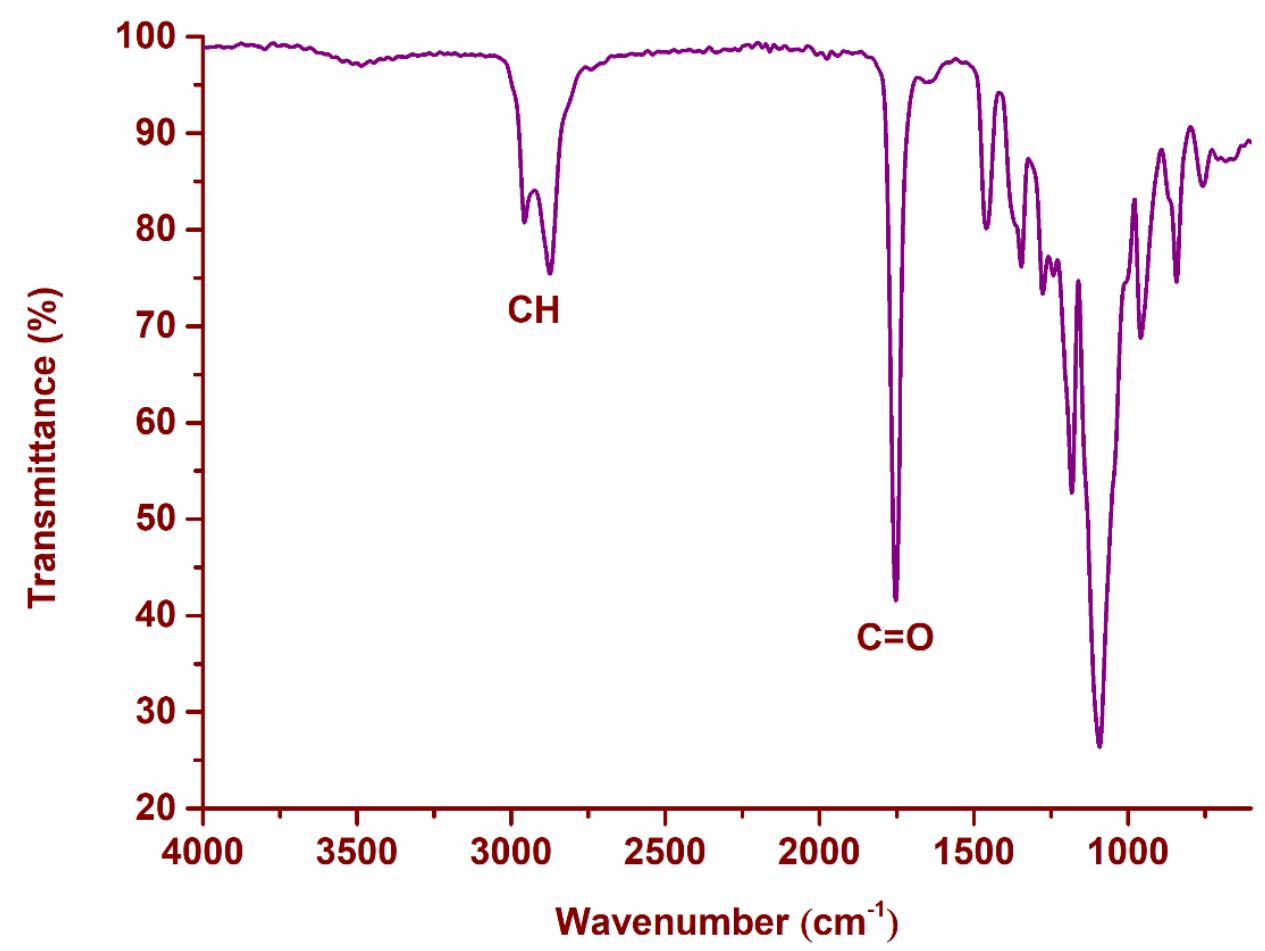

Figure S8. ATR-FTIR spectrum of MePEG-PIBL 8. 


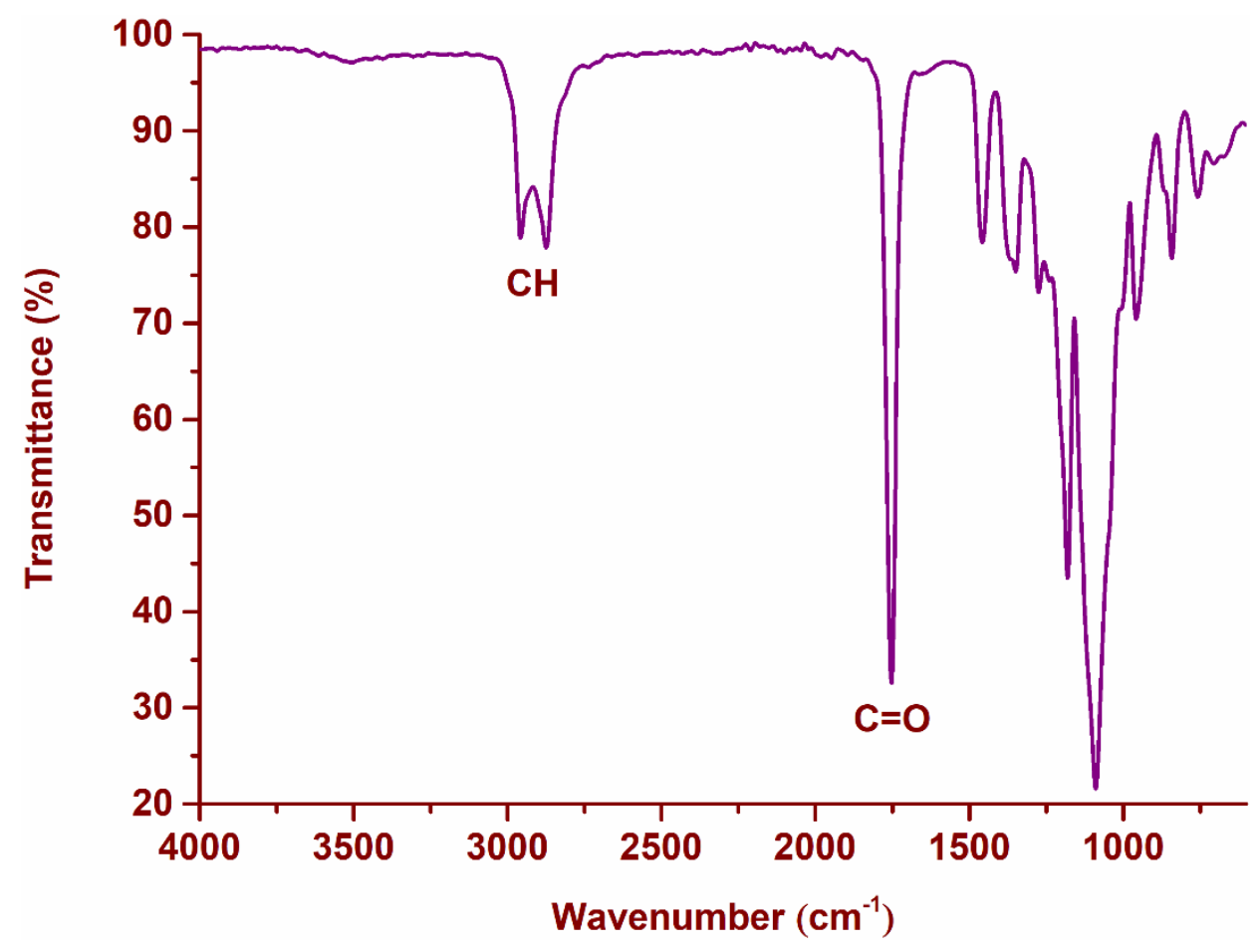

Figure S9. ATR-FTIR spectrum of MePEG-PIBL 9.

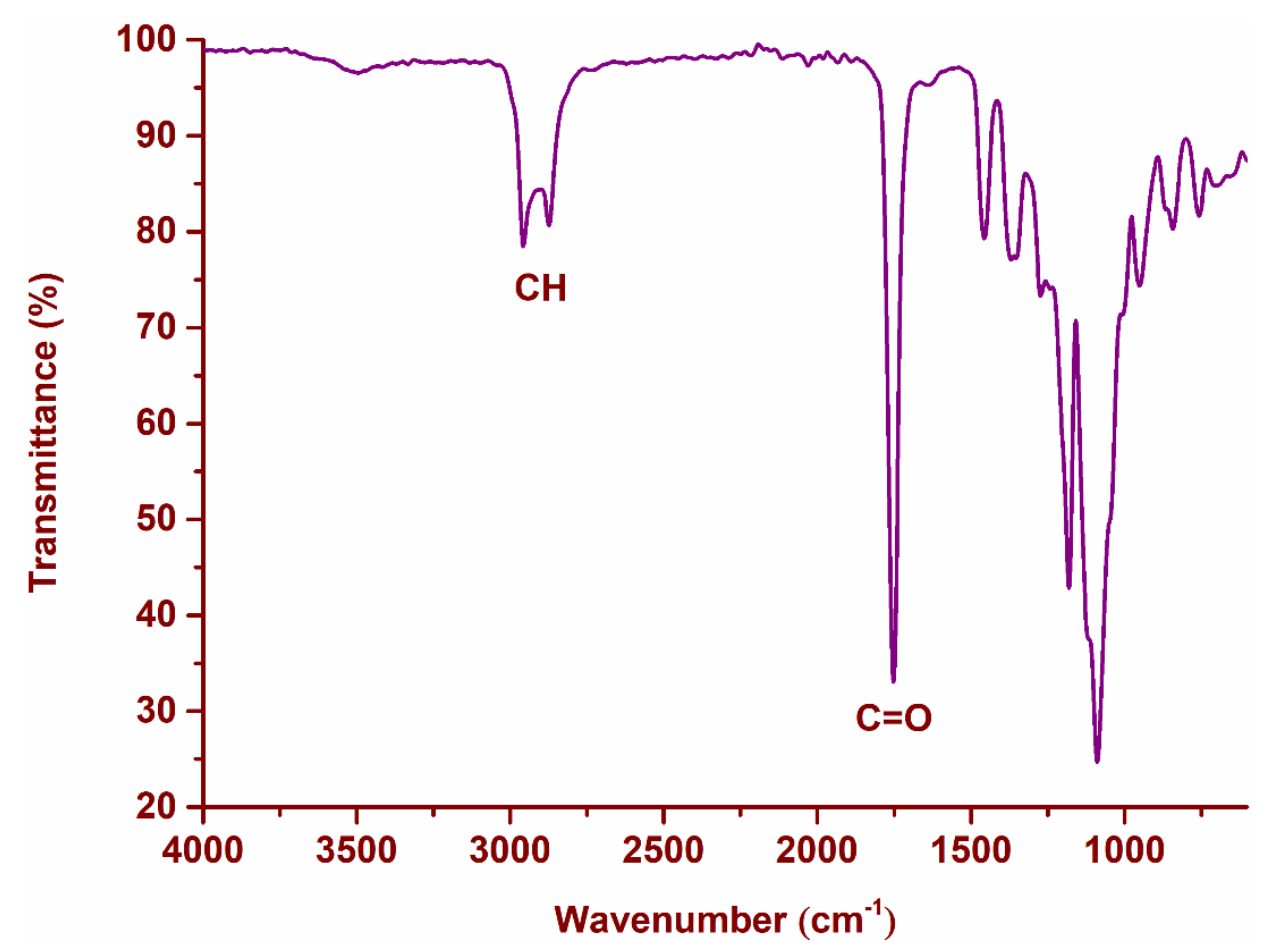

Figure S10. ATR-FTIR spectrum of MePEG-PIBL 10. 


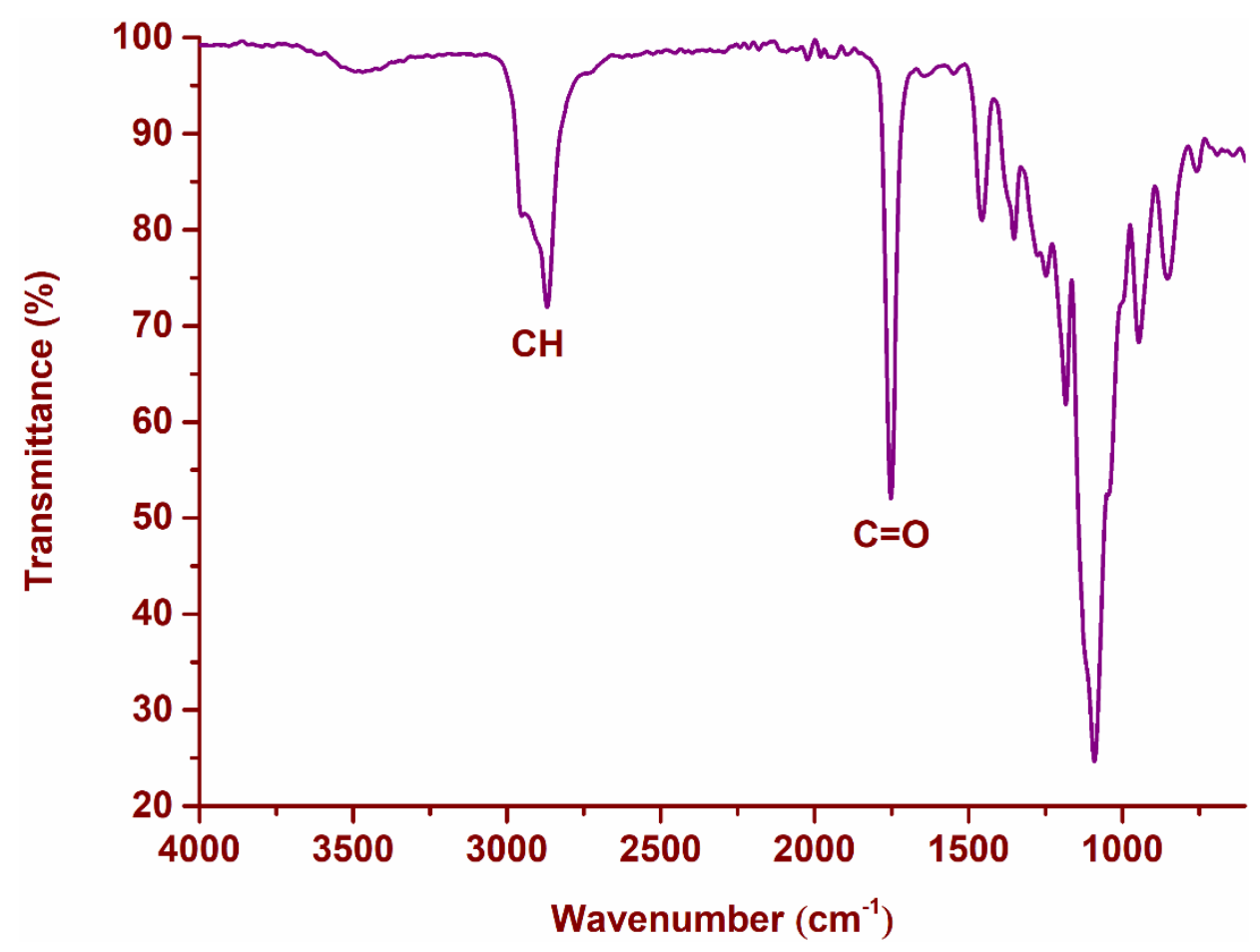

Figure S11. ATR-FTIR spectrum of PIBL-PEG-PIBL 11.

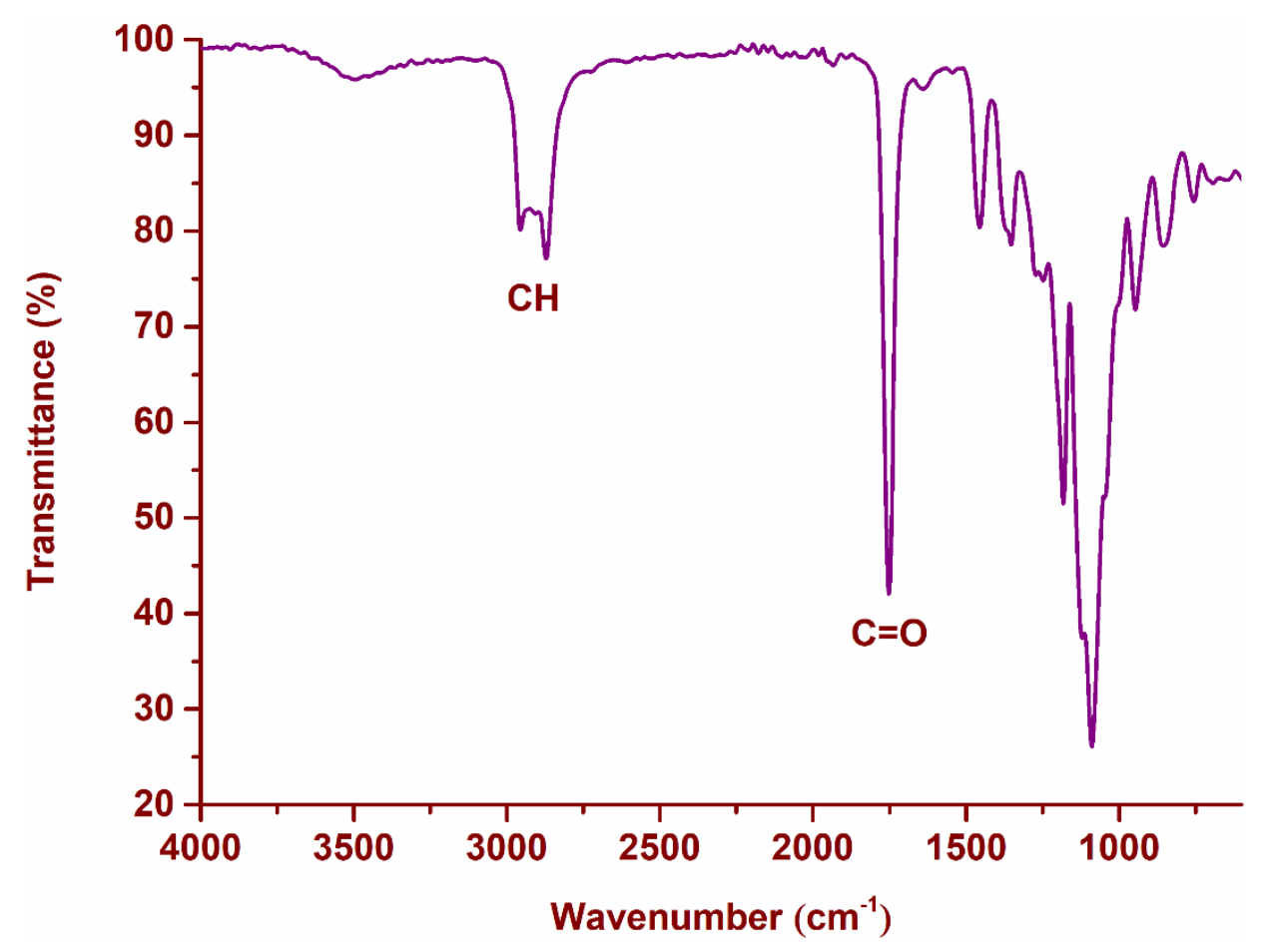

Figure S12. ATR-FTIR spectrum of PIBL-PEG-PIBL 12. 


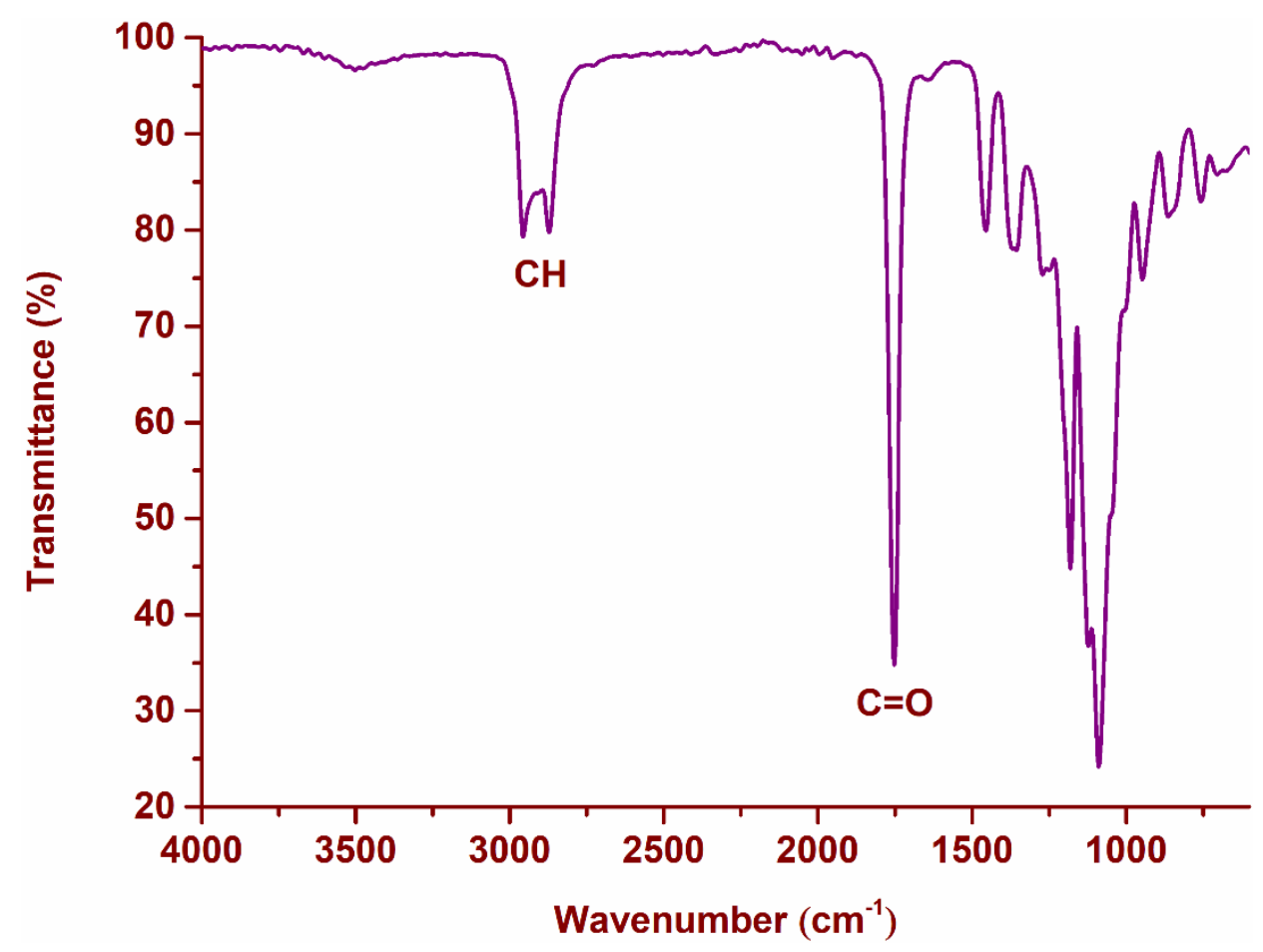

Figure S13. ATR-FTIR spectrum of PIBL-PEG-PIBL 13.

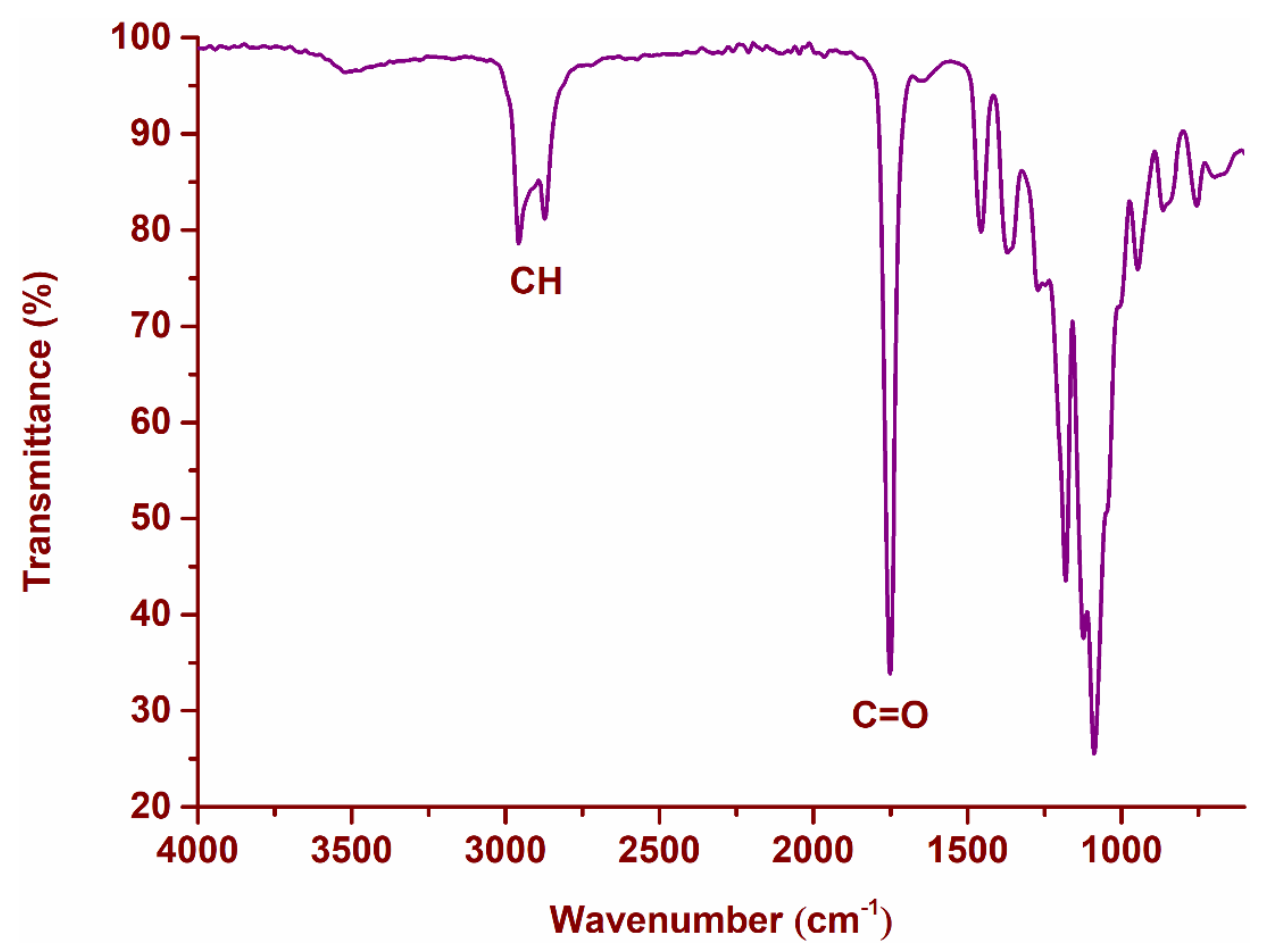

Figure S14. ATR-FTIR spectrum of PIBL-PEG-PIBL 14. 


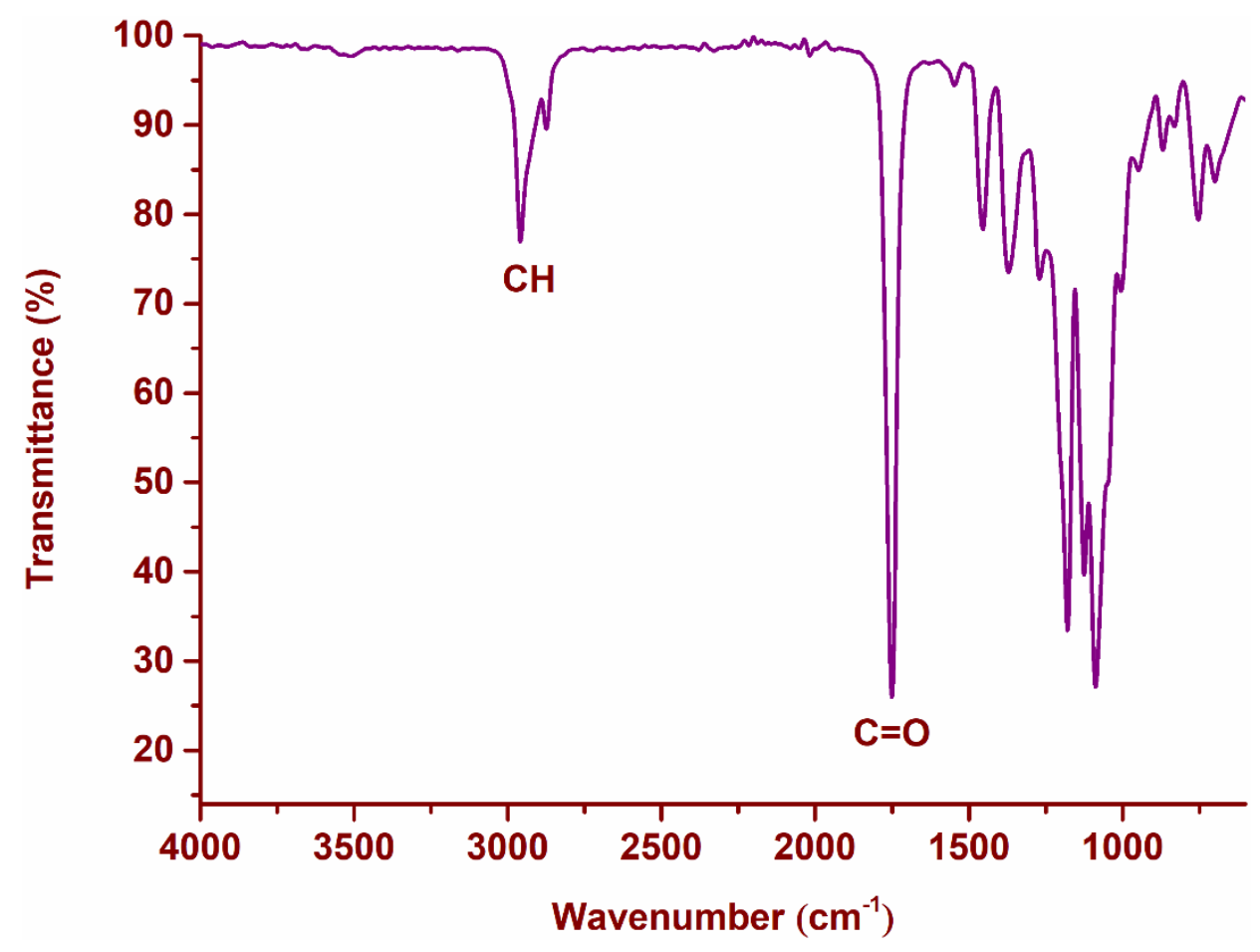

Figure S15. ATR-FTIR spectrum of PIBL homopolymer 19.

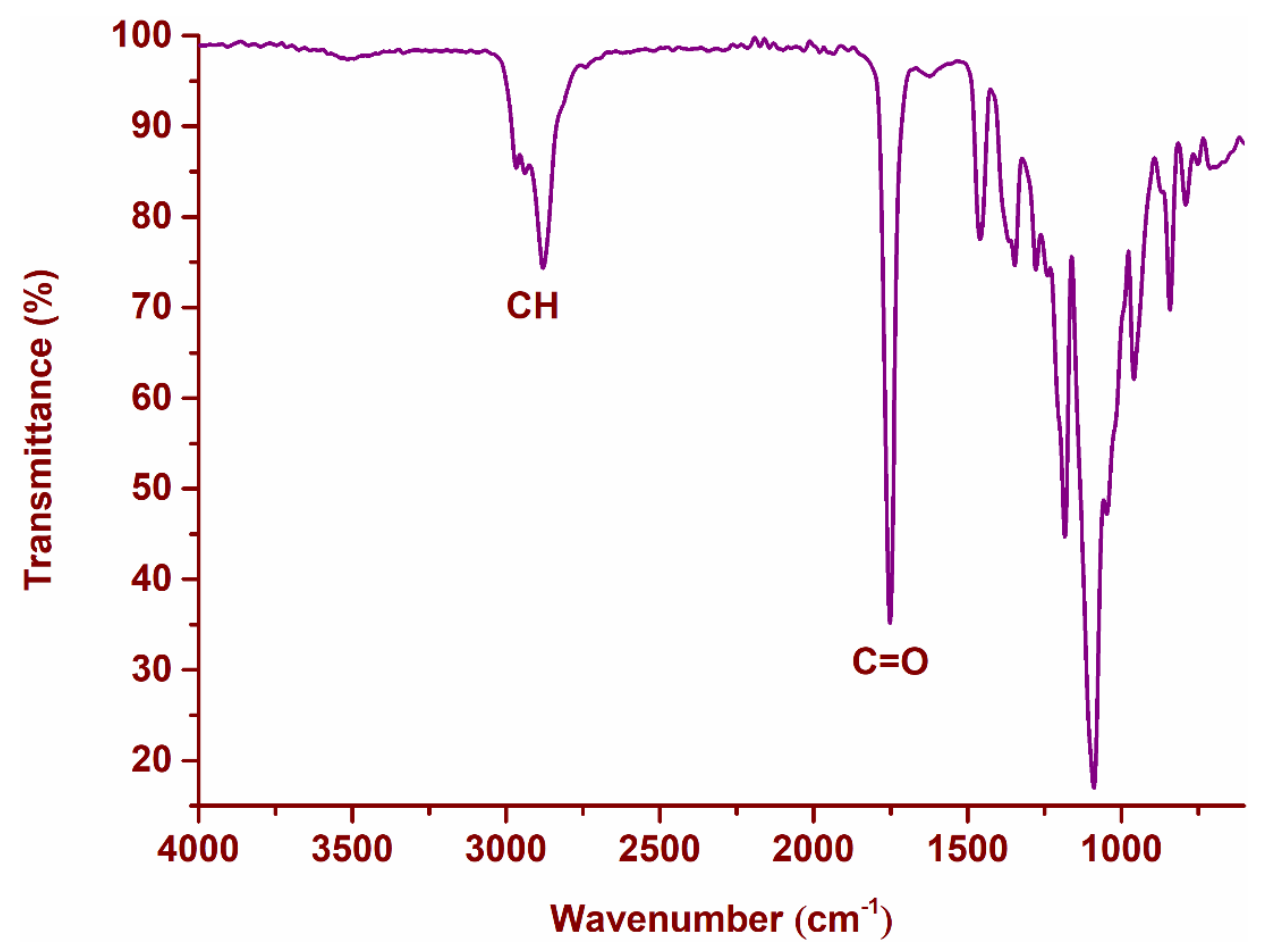

Figure S16. ATR-FTIR spectrum of MePEG-PIPL diblock copolymer. 


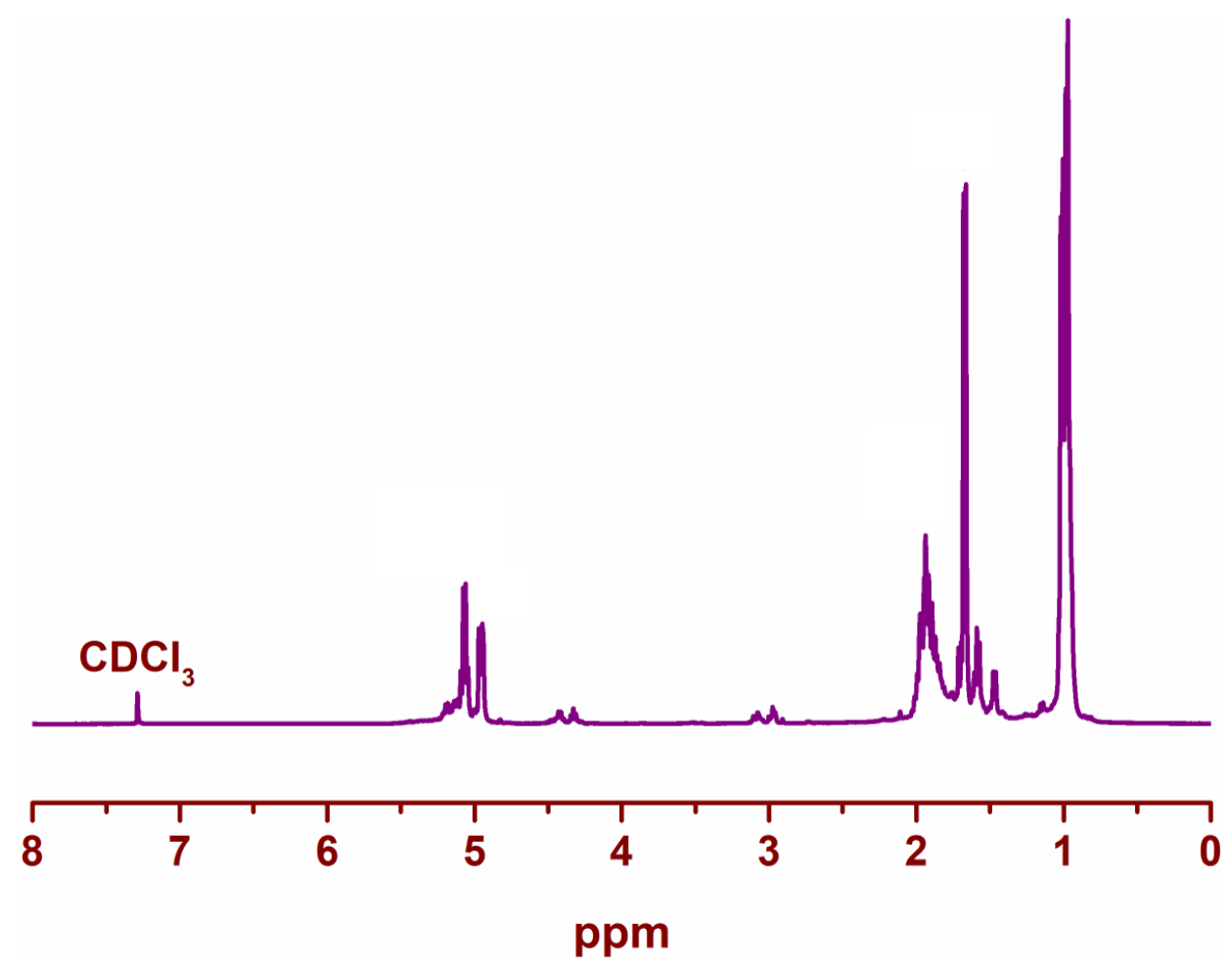

Figure S17. ${ }^{1} \mathrm{H}$ NMR spectrum of crude mixture of IBL 4.

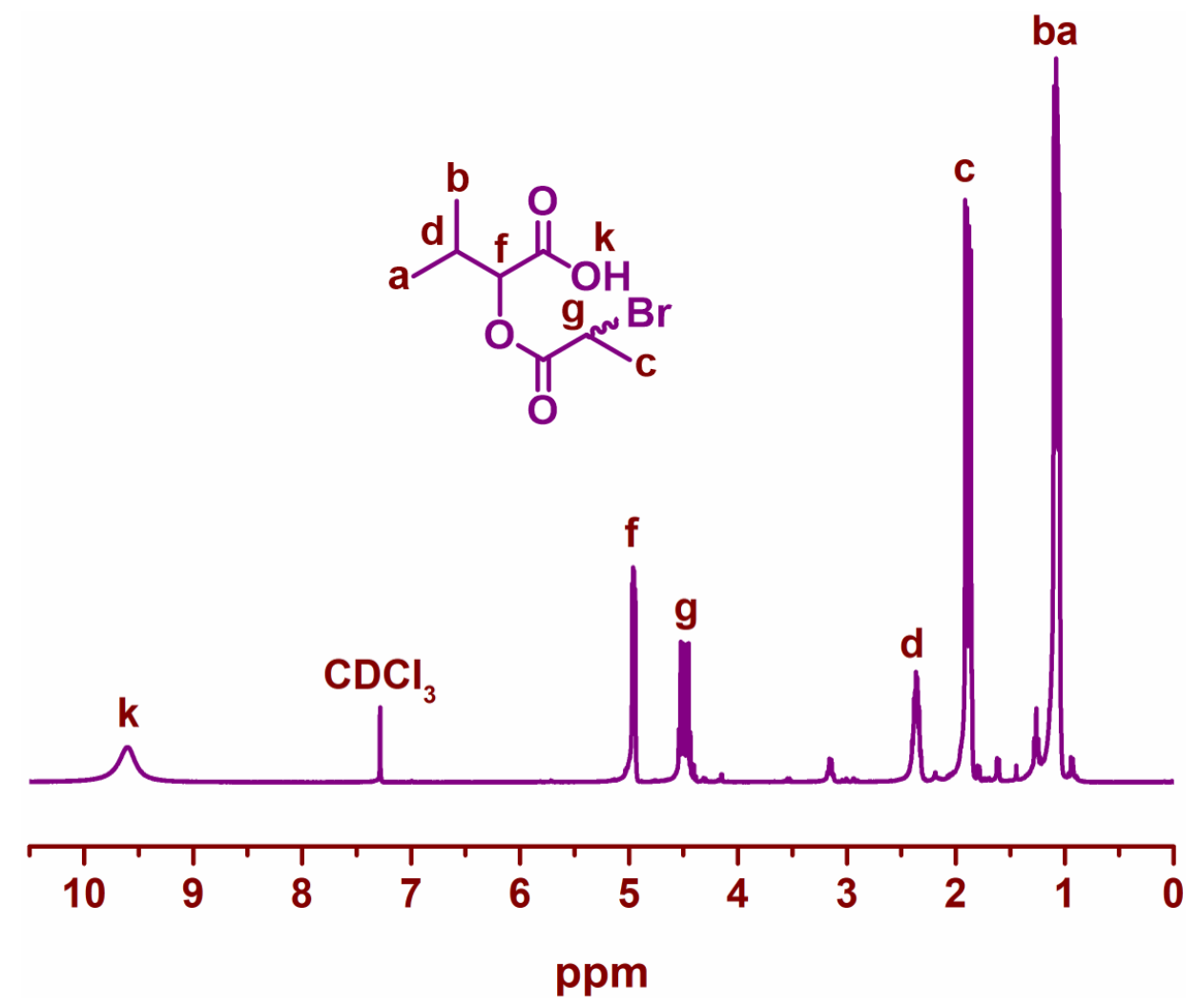

Figure S18. ${ }^{1} \mathrm{H}$ NMR spectrum of 2-((2-bromopropanoyl)oxy)-3methylbutanoic acid. 


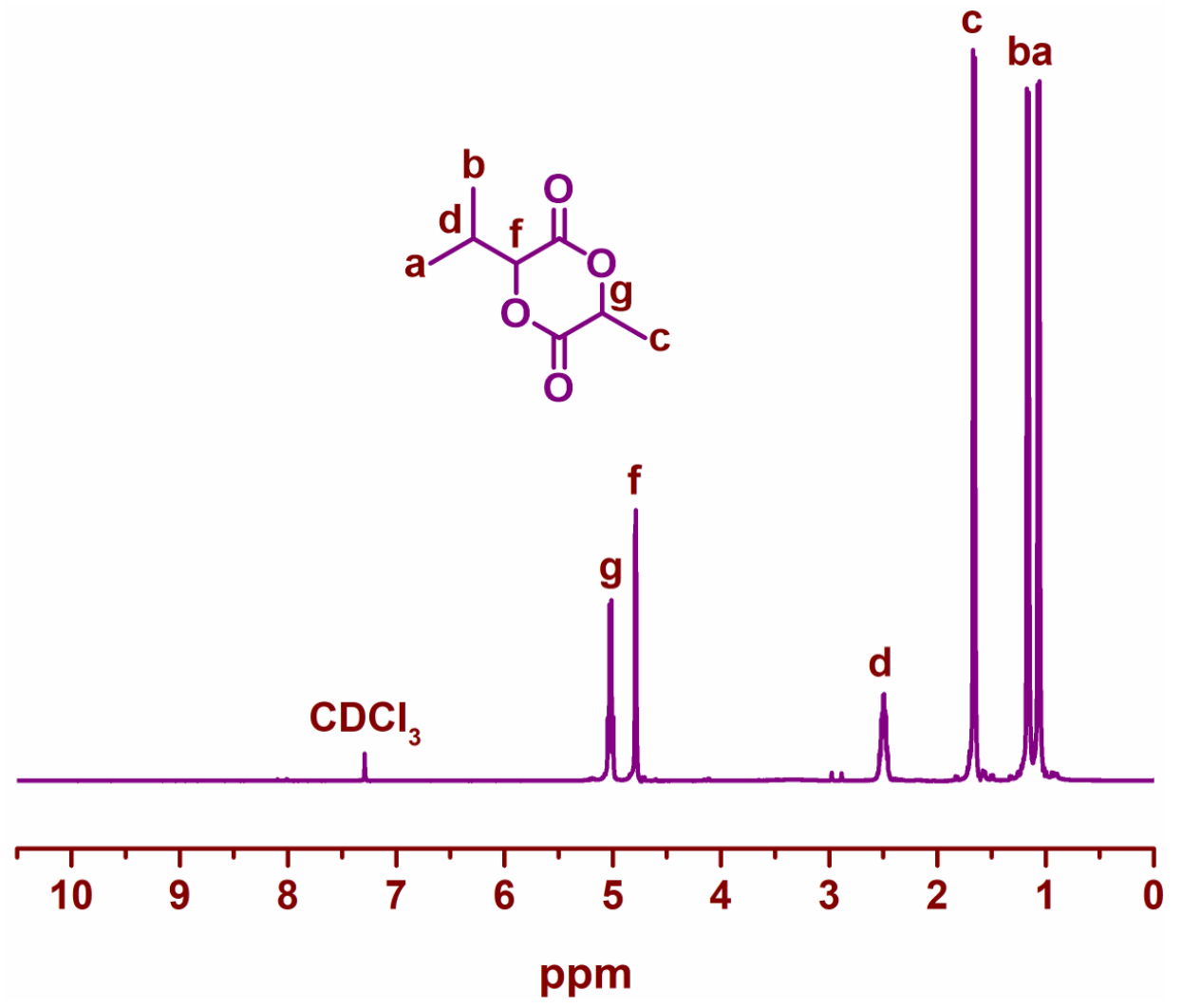

Figure S19. ${ }^{1} \mathrm{H}$ NMR spectrum of 3-isopropyl-6-methyl-1,4-dioxane-2,5dione (isopropyl lactide, IPL).

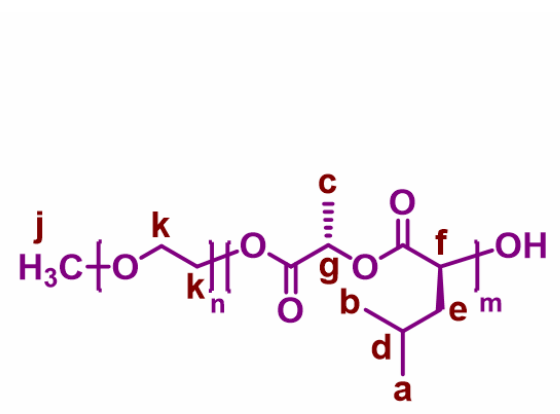

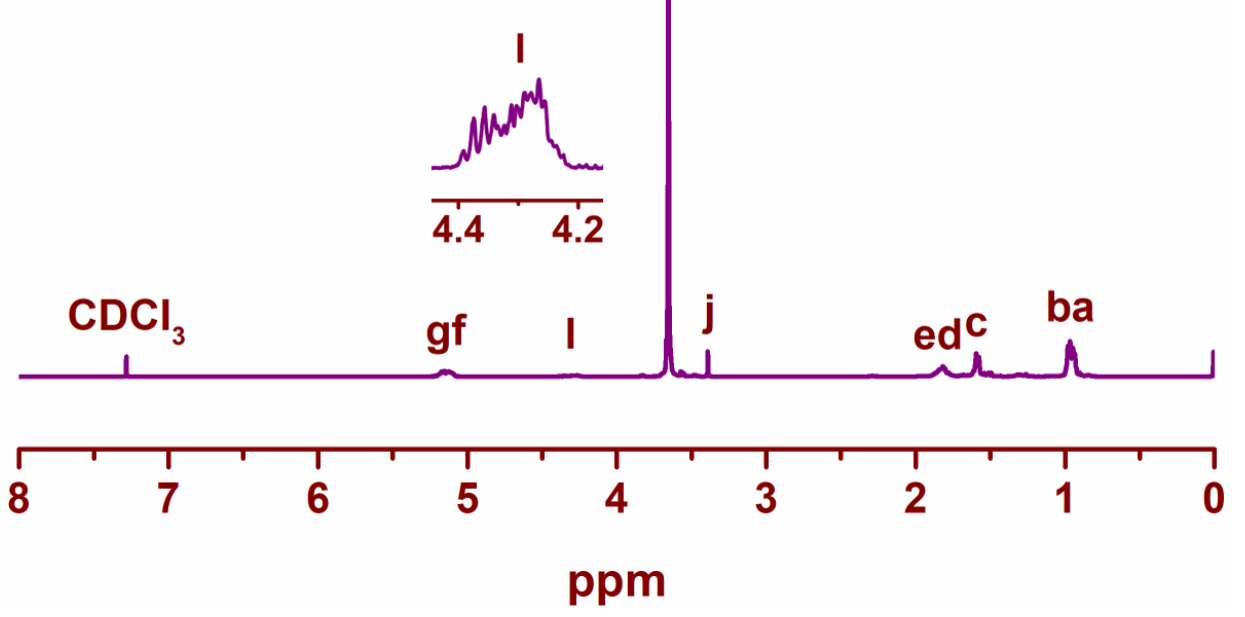

Figure S20. ${ }^{1} \mathrm{H}$ NMR spectrum of MePEG-PIBL 7. 

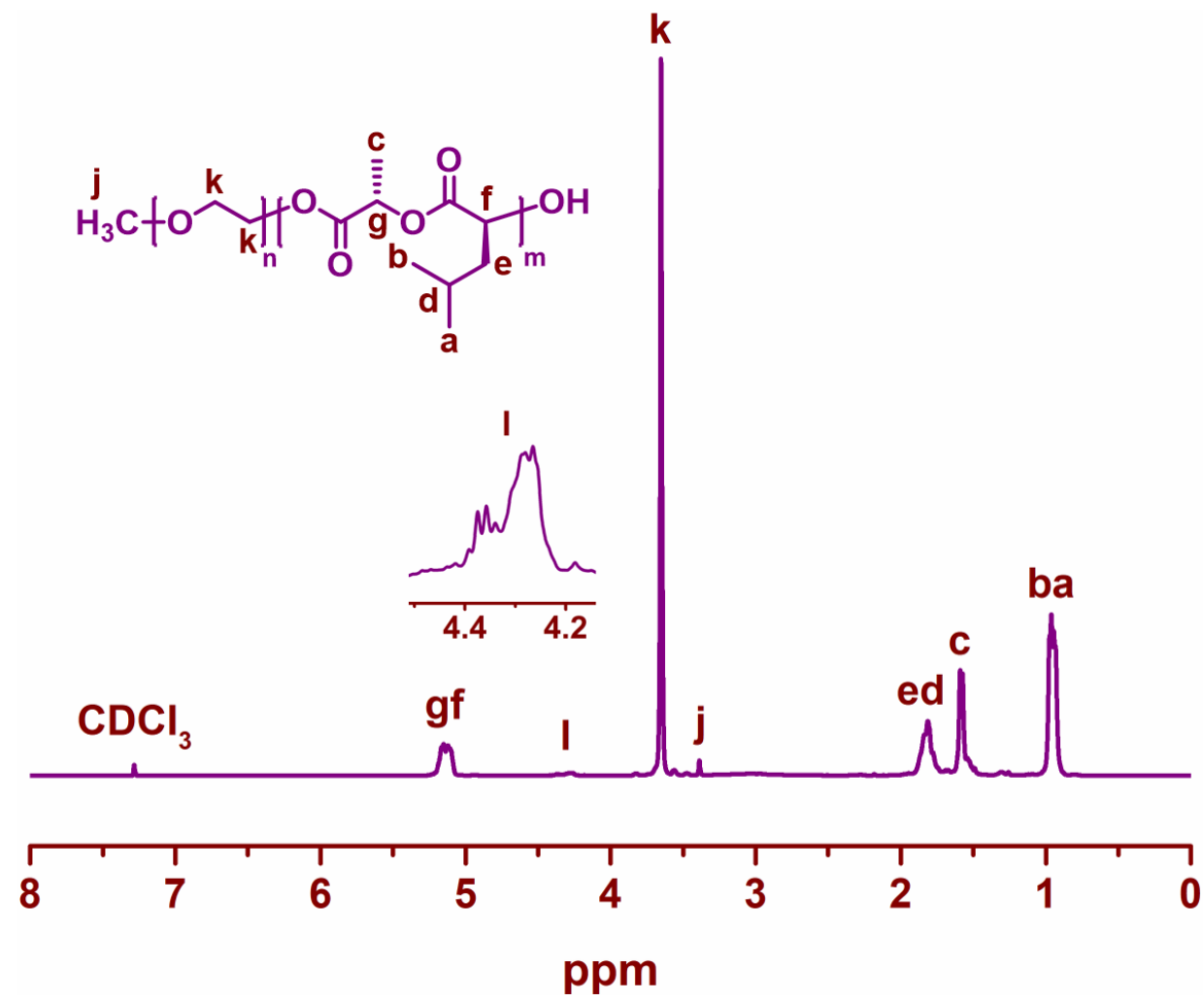

Figure S21. ${ }^{1} \mathrm{H}$ NMR spectrum of MePEG-PIBL 9.

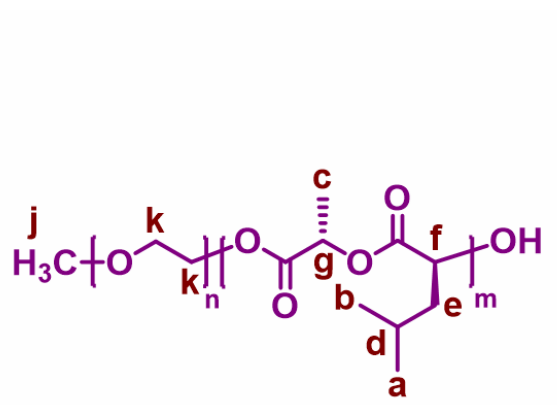
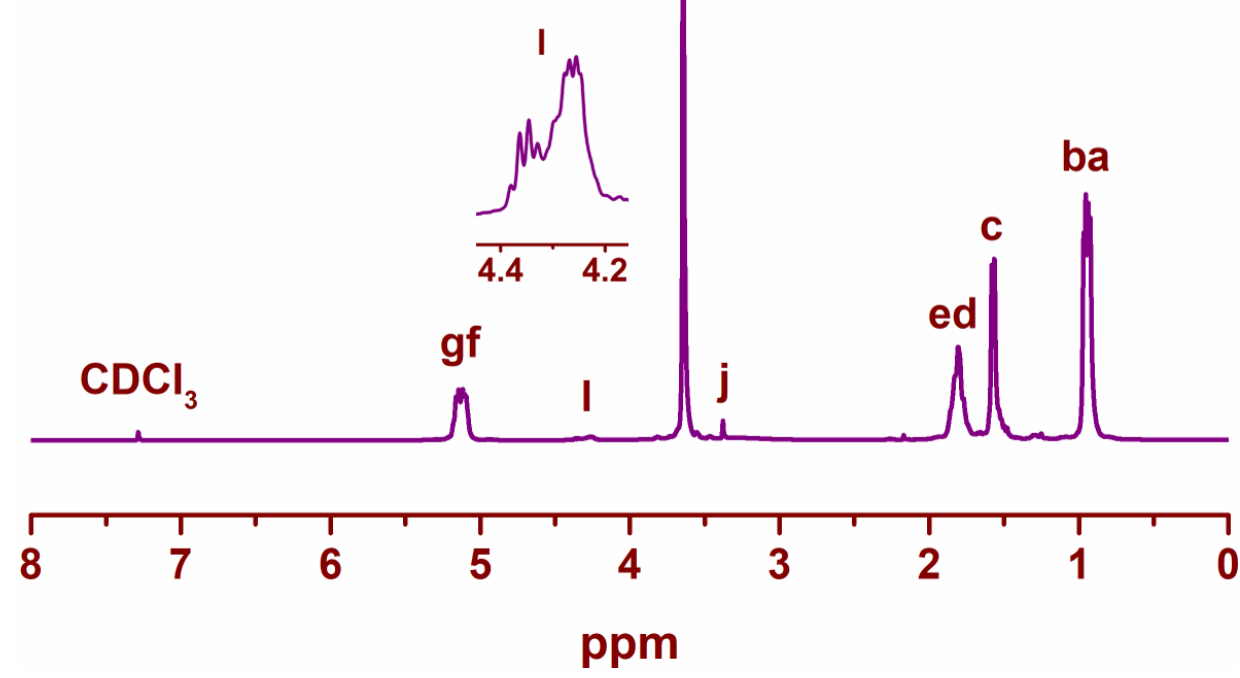

Figure S22. ${ }^{1} \mathrm{H}$ NMR spectrum of MePEG-PIBL 10. 


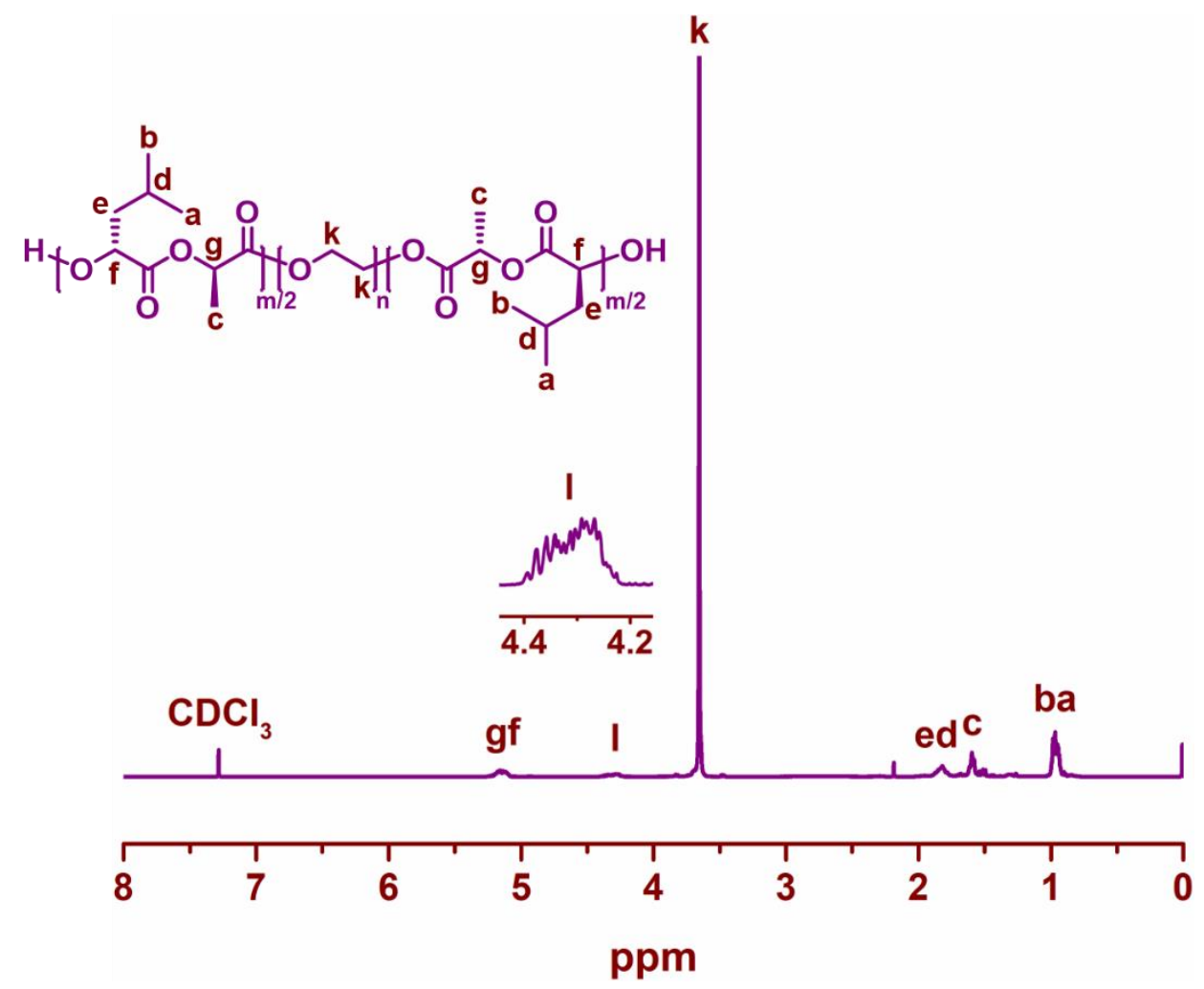

Figure S23. ${ }^{1} \mathrm{H}$ NMR spectrum of PIBL-PEG-PIBL 11.

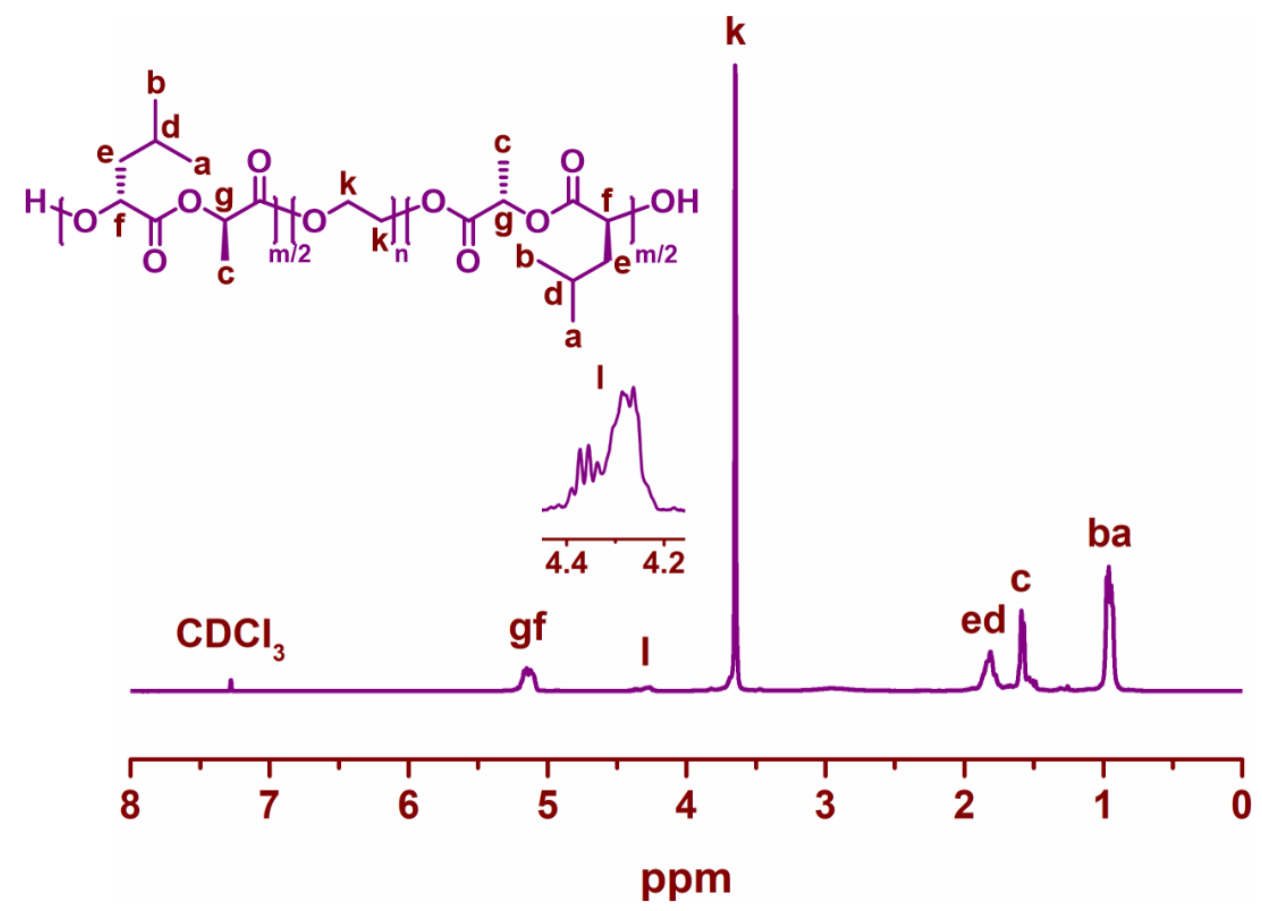

Figure S24. ${ }^{1} \mathrm{H}$ NMR spectrum of PIBL-PEG-PIBL 13. 


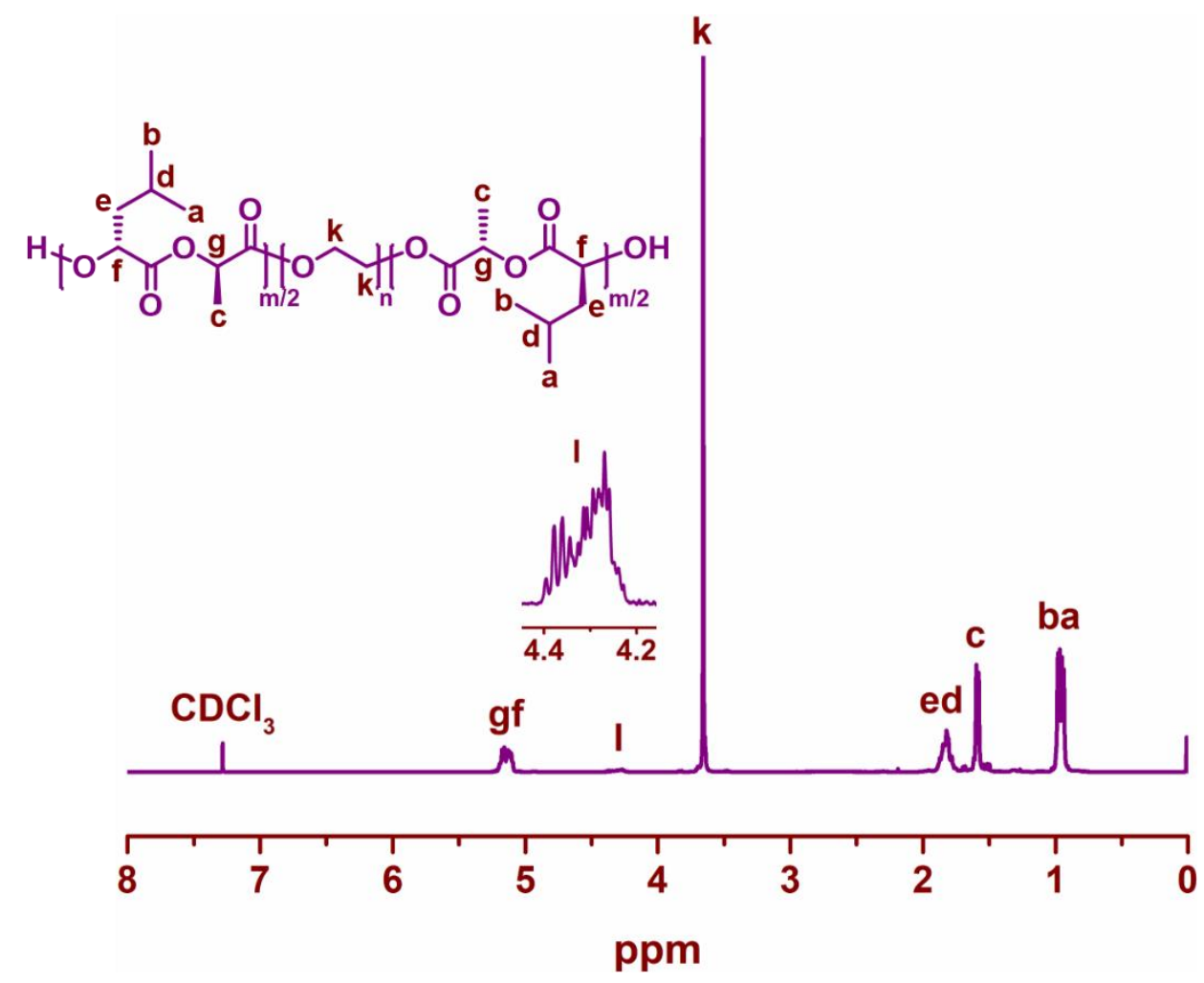

Figure S25. ${ }^{1} \mathrm{H}$ NMR spectrum of PIBL-PEG-PIBL 14.

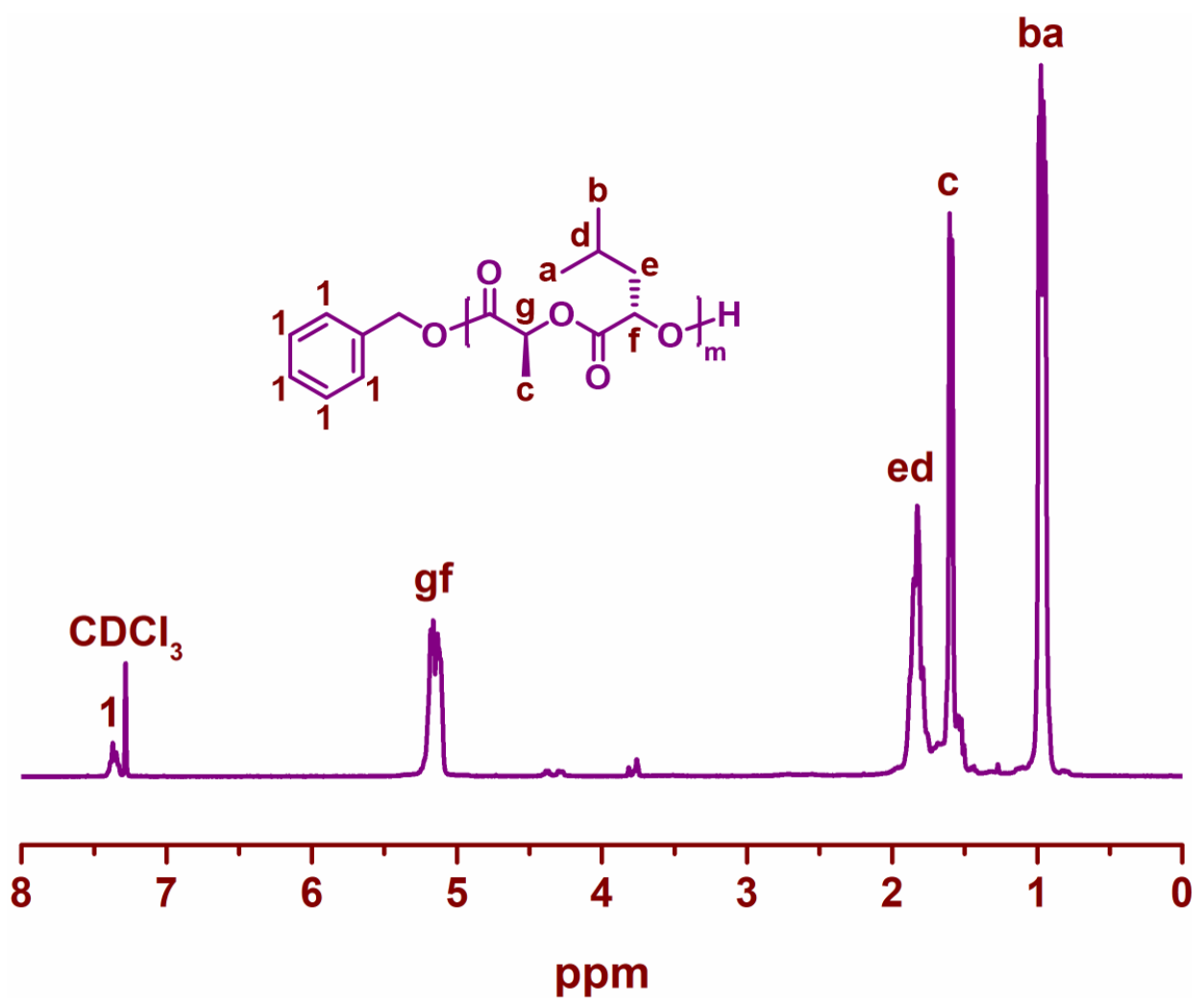

Figure S26. ${ }^{1} \mathrm{H}$ NMR spectrum of PIBL homopolymer 19. 


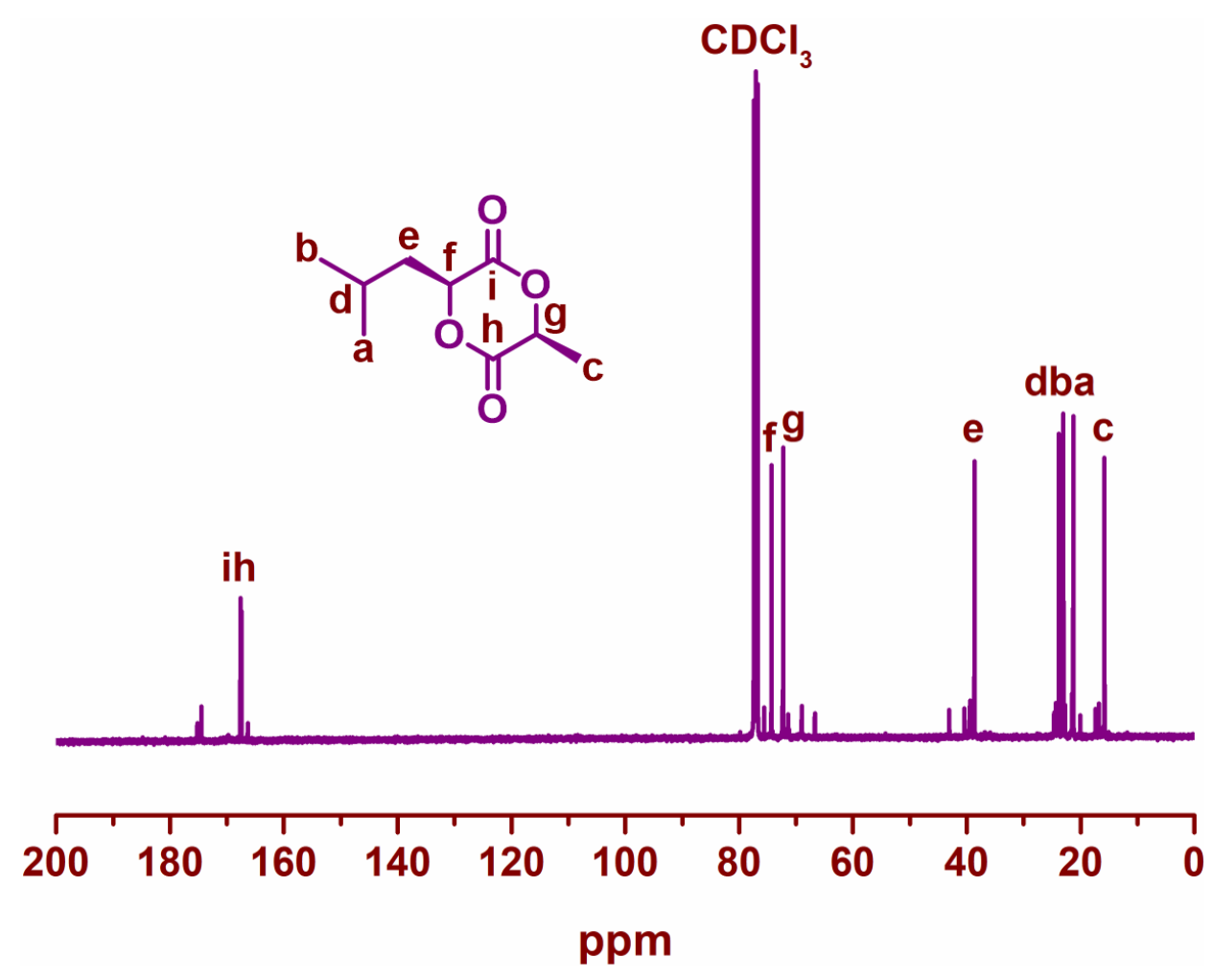

Figure S27. ${ }^{13} \mathrm{C}$ NMR spectrum of crude mixture of IBL 4.

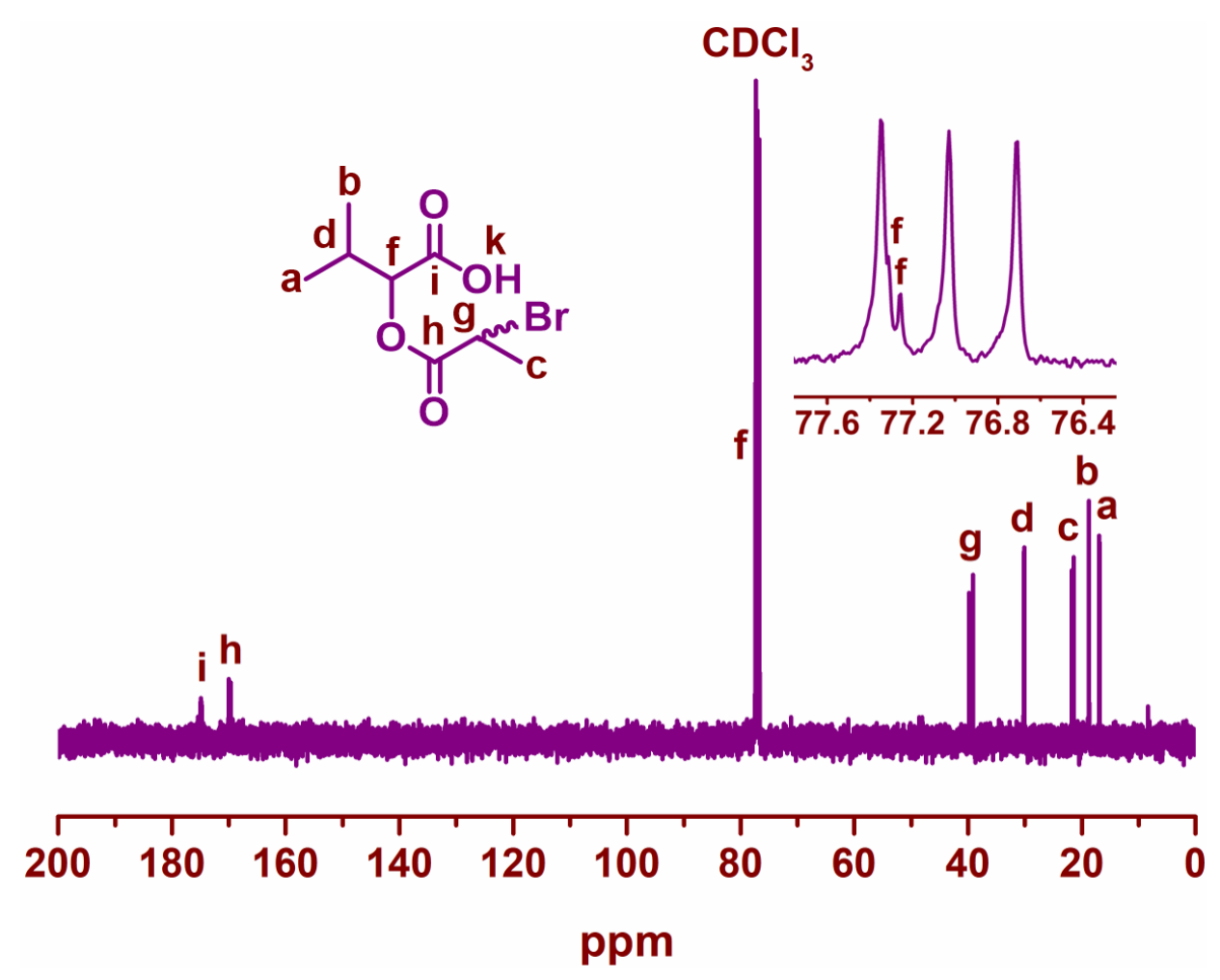

Figure S28. ${ }^{13} \mathrm{C}$ NMR spectrum of 2-((2-bromopropanoyl)oxy)-3methylbutanoic acid. 


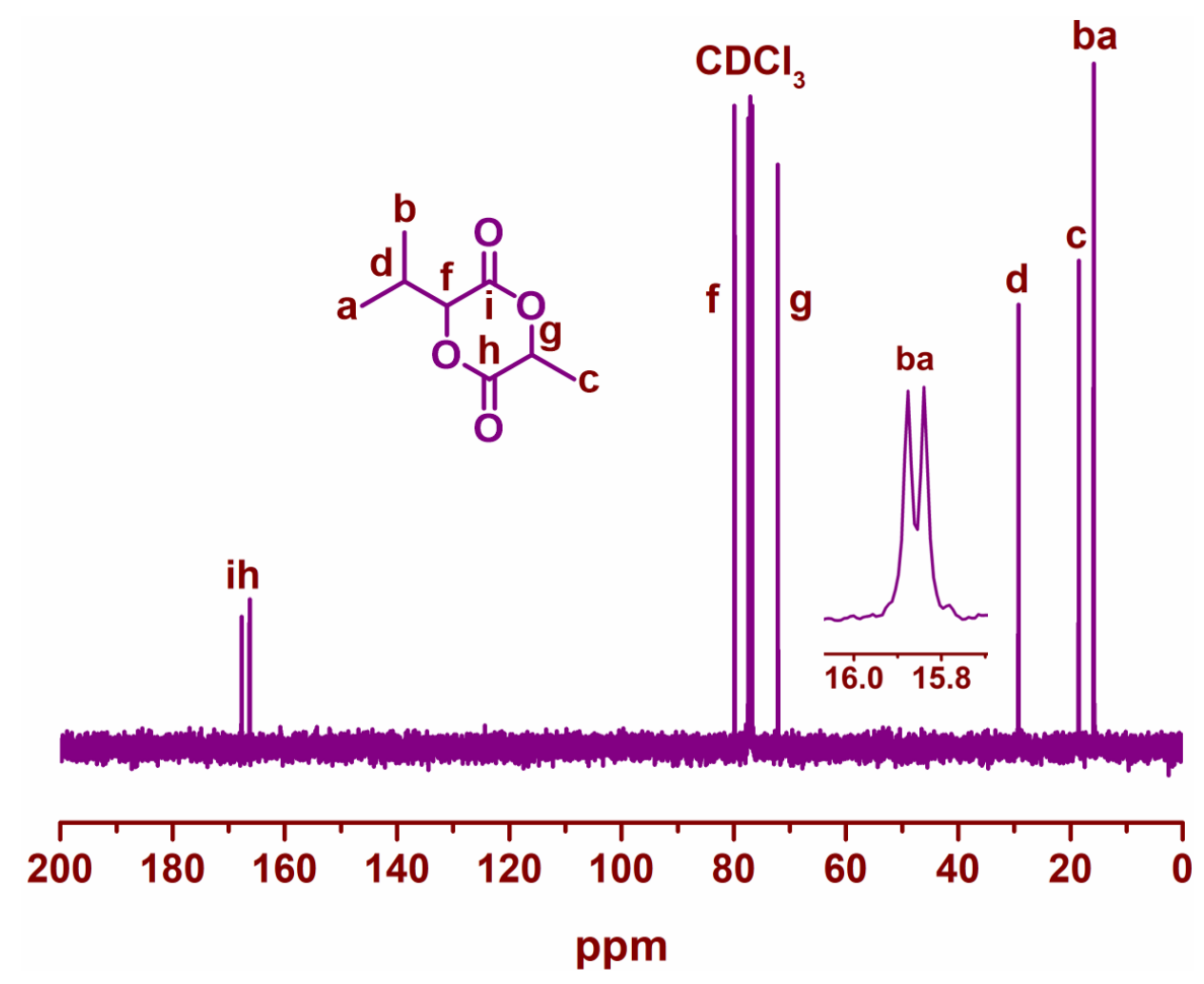

Figure S29. ${ }^{13} \mathrm{C}$ NMR spectrum of 3-isopropyl-6-methyl-1,4-dioxane-2,5dione (isopropyl lactide, IPL).

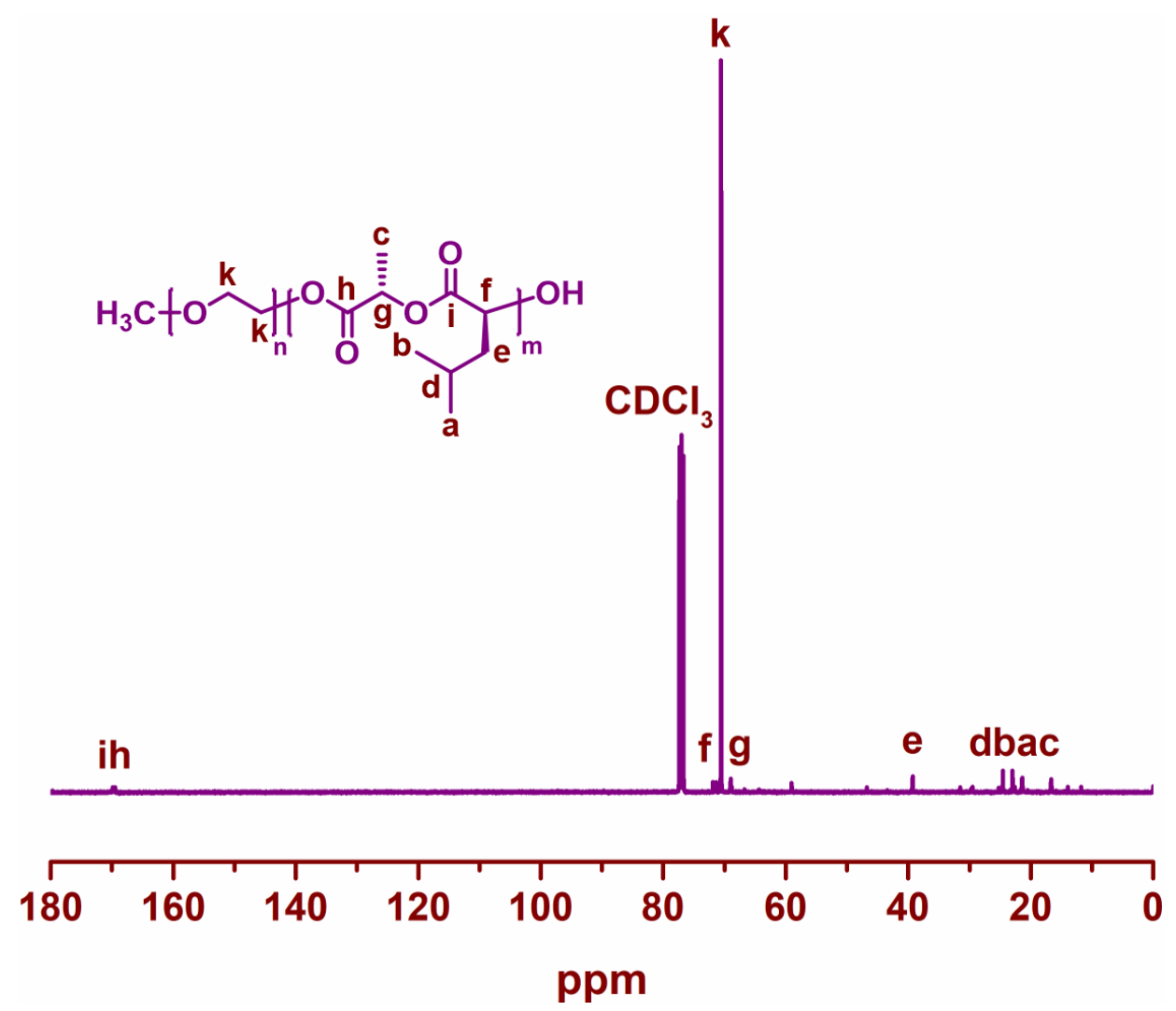

Figure S30. ${ }^{13} \mathrm{C}$ NMR spectrum of MePEG-PIBL 7. 

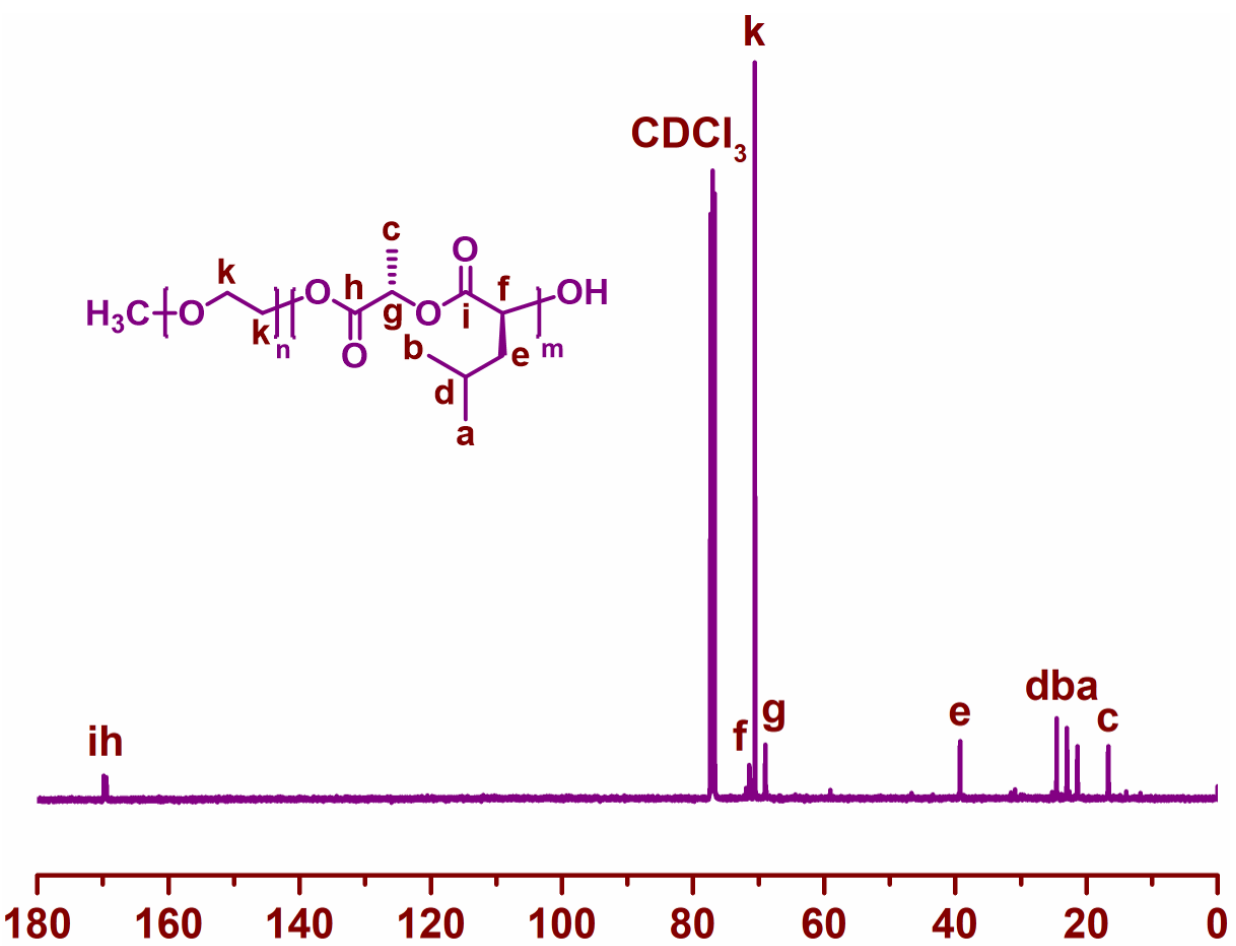

ppm

Figure S31. ${ }^{13} \mathrm{C}$ NMR spectrum of MePEG-PIBL 9.

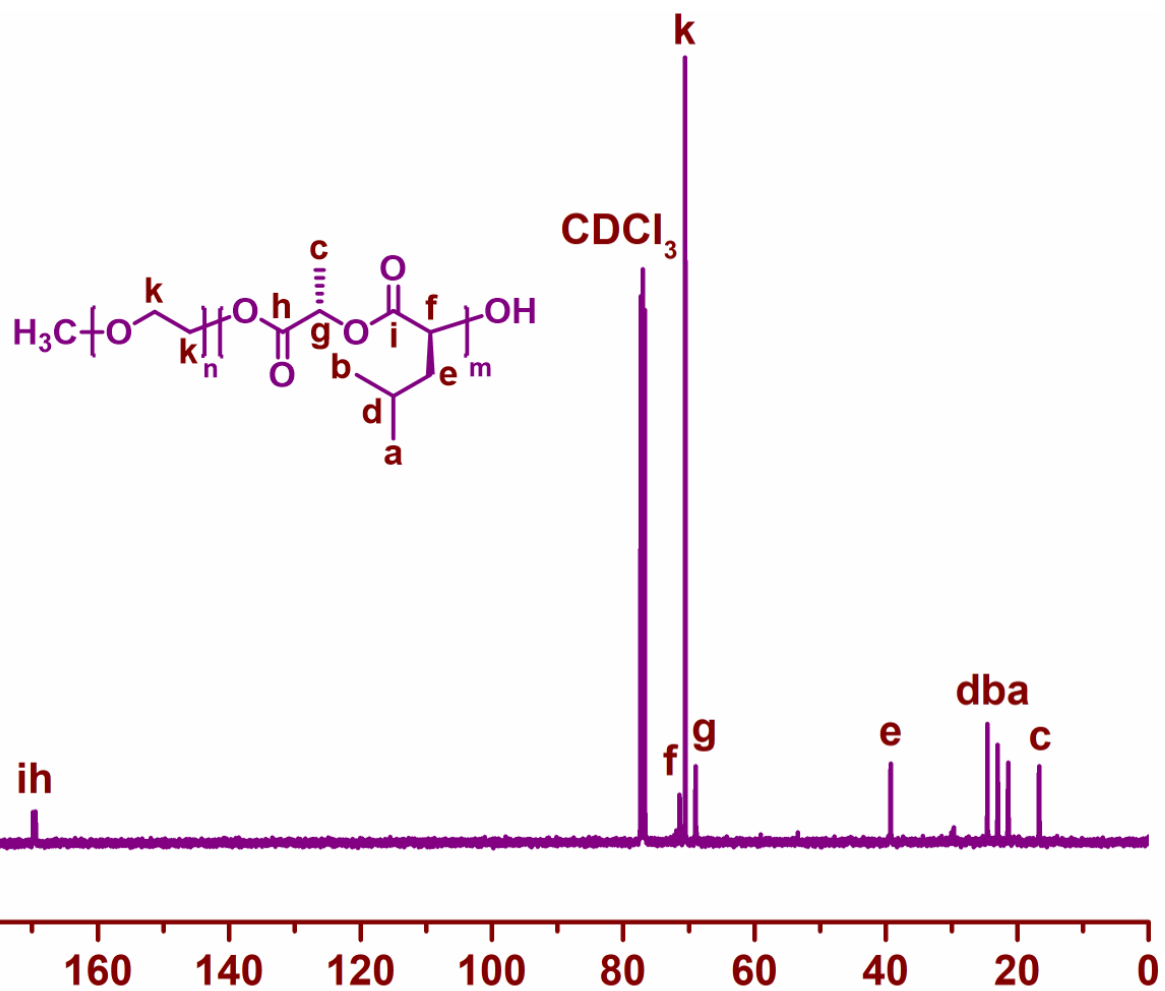

ppm

Figure S32. ${ }^{13} \mathrm{C}$ NMR spectrum of MePEG-PIBL 10. 


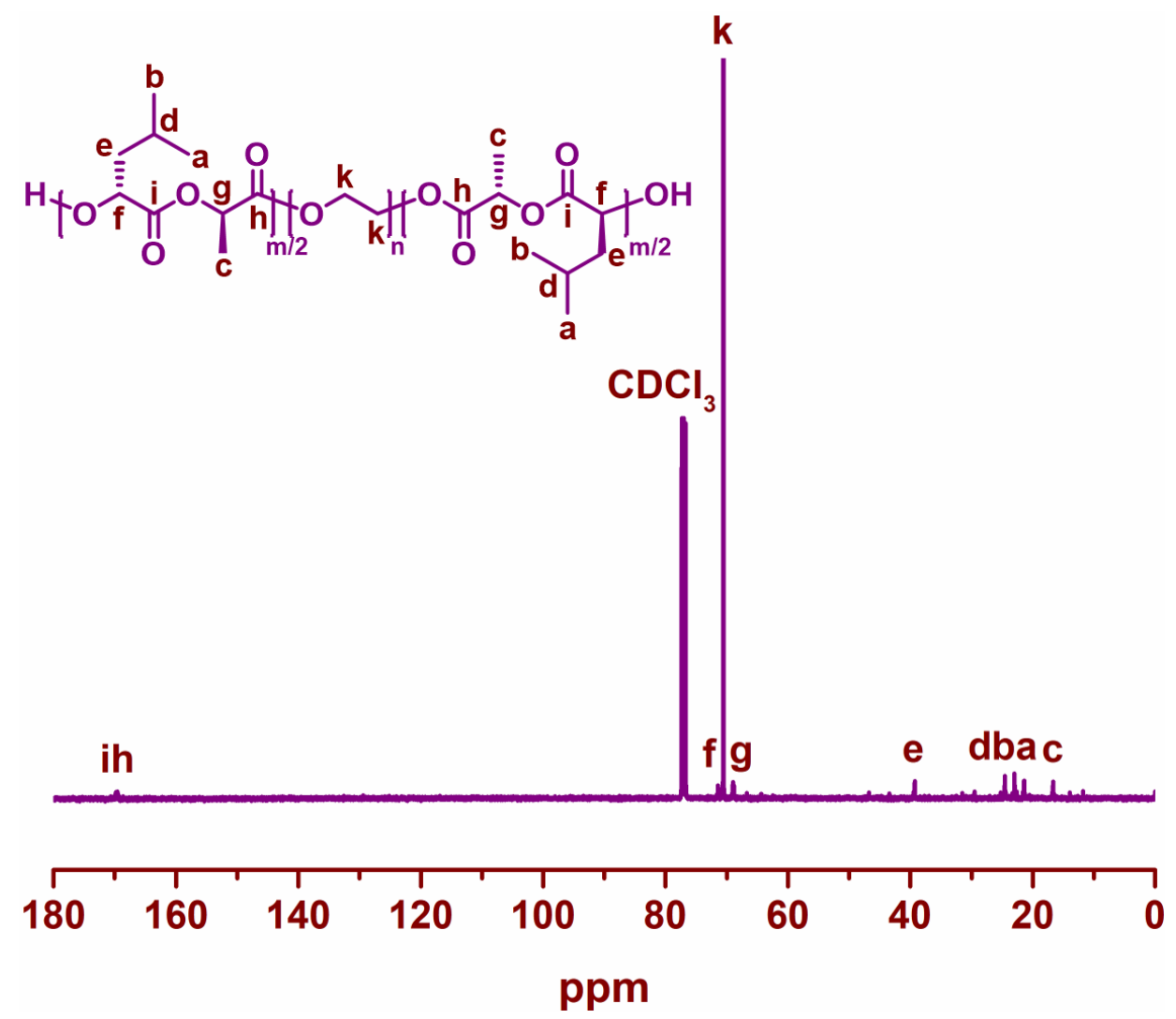

Figure S33. ${ }^{13} \mathrm{C}$ NMR spectrum of PIBL-PEG-PIBL 11.

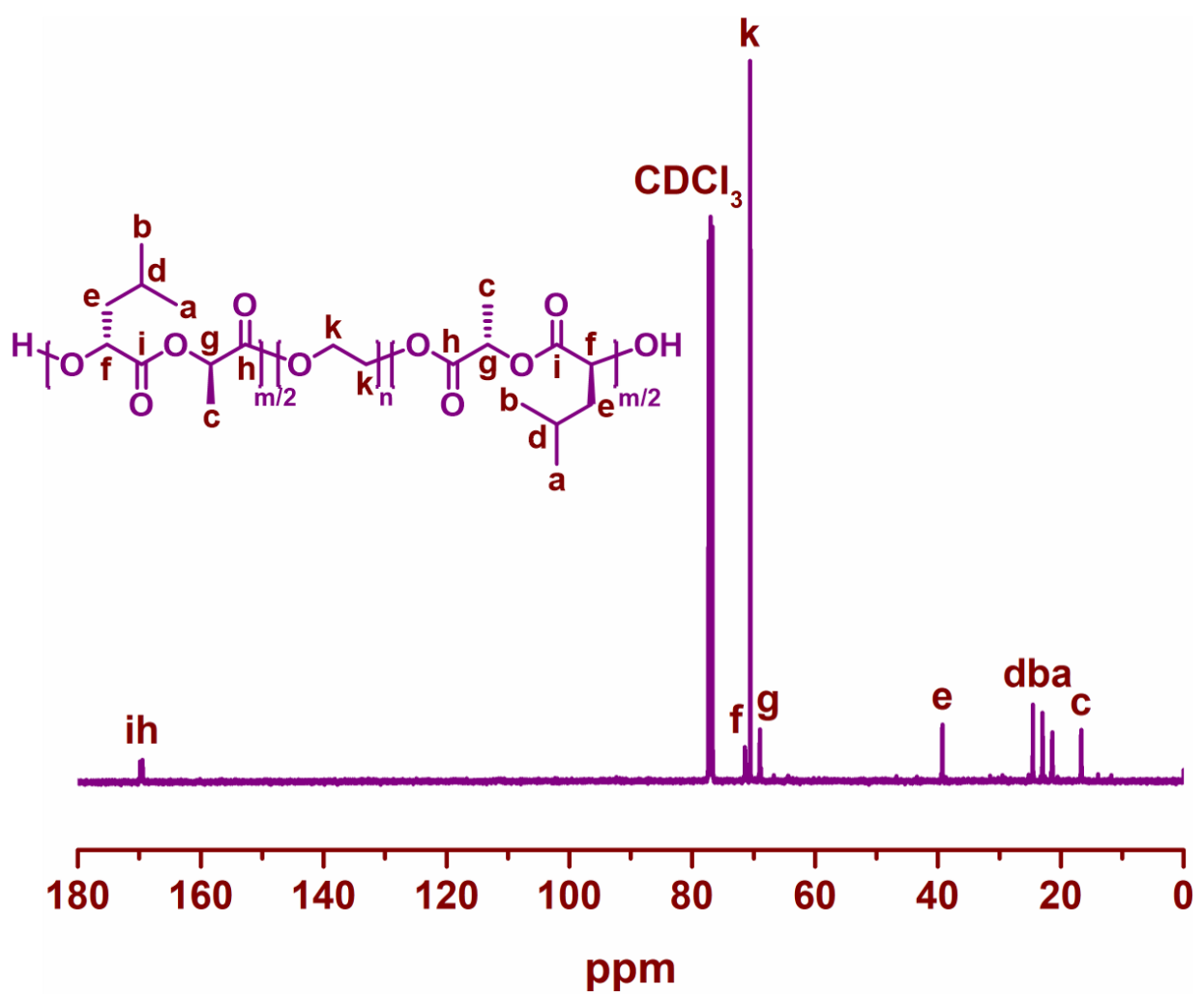

Figure S34. ${ }^{13} \mathrm{C}$ NMR spectrum of PIBL-PEG-PIBL 13. 


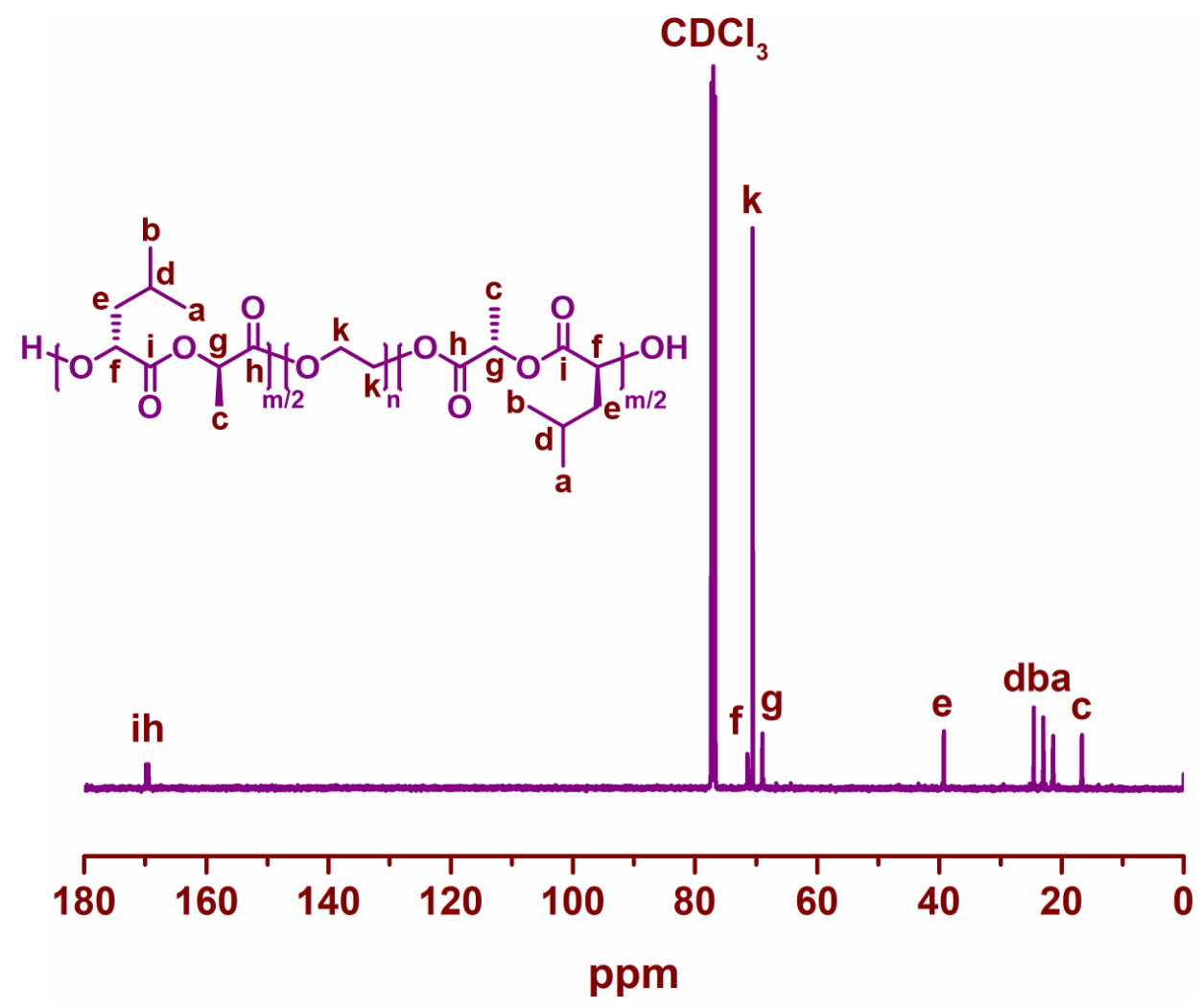

Figure S35. ${ }^{13} \mathrm{C}$ NMR spectrum of PIBL-PEG-PIBL 14. 
Mechanistic Approaches Towards Polymerization of Asymmetrical Glycolides
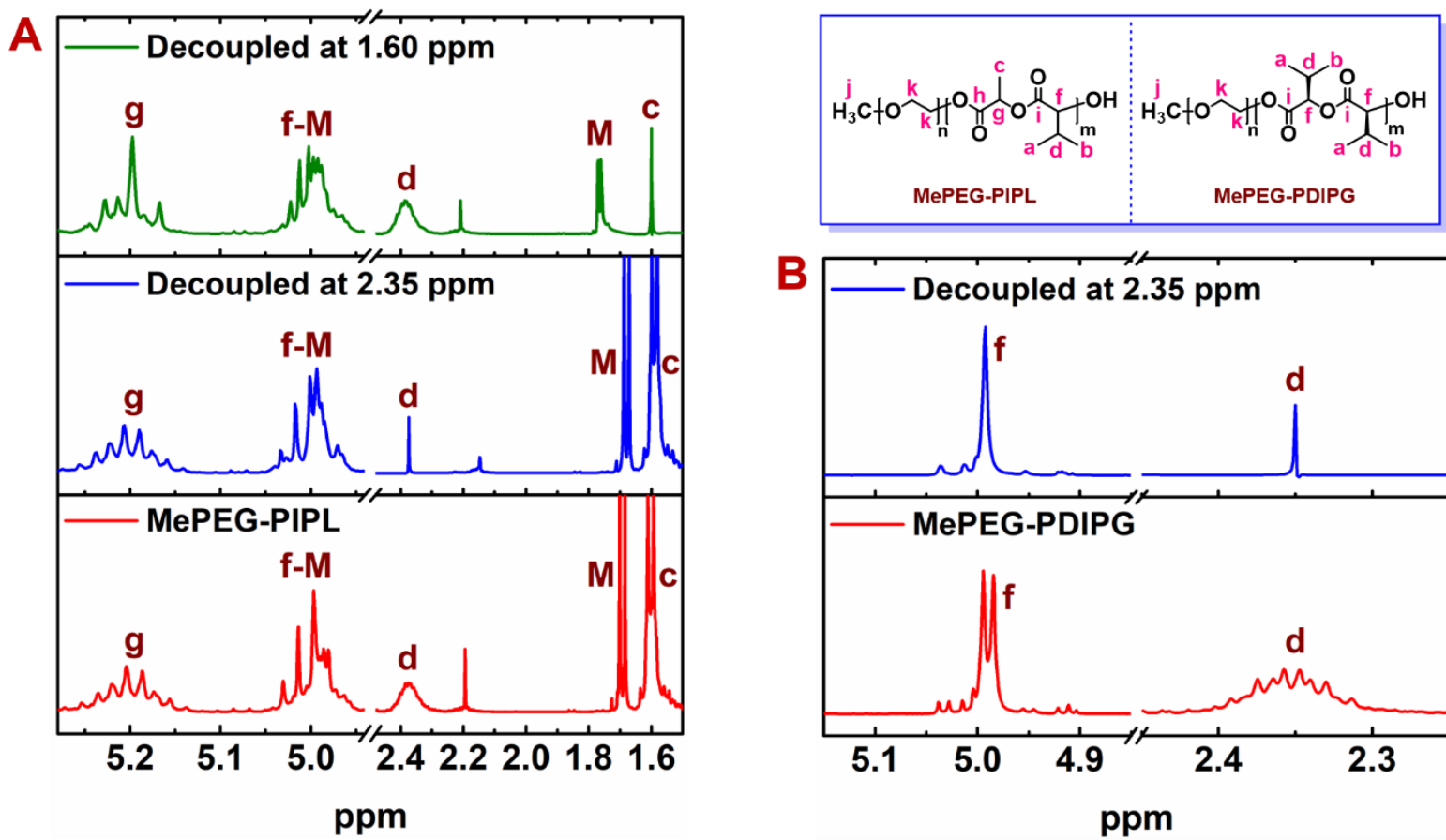

B
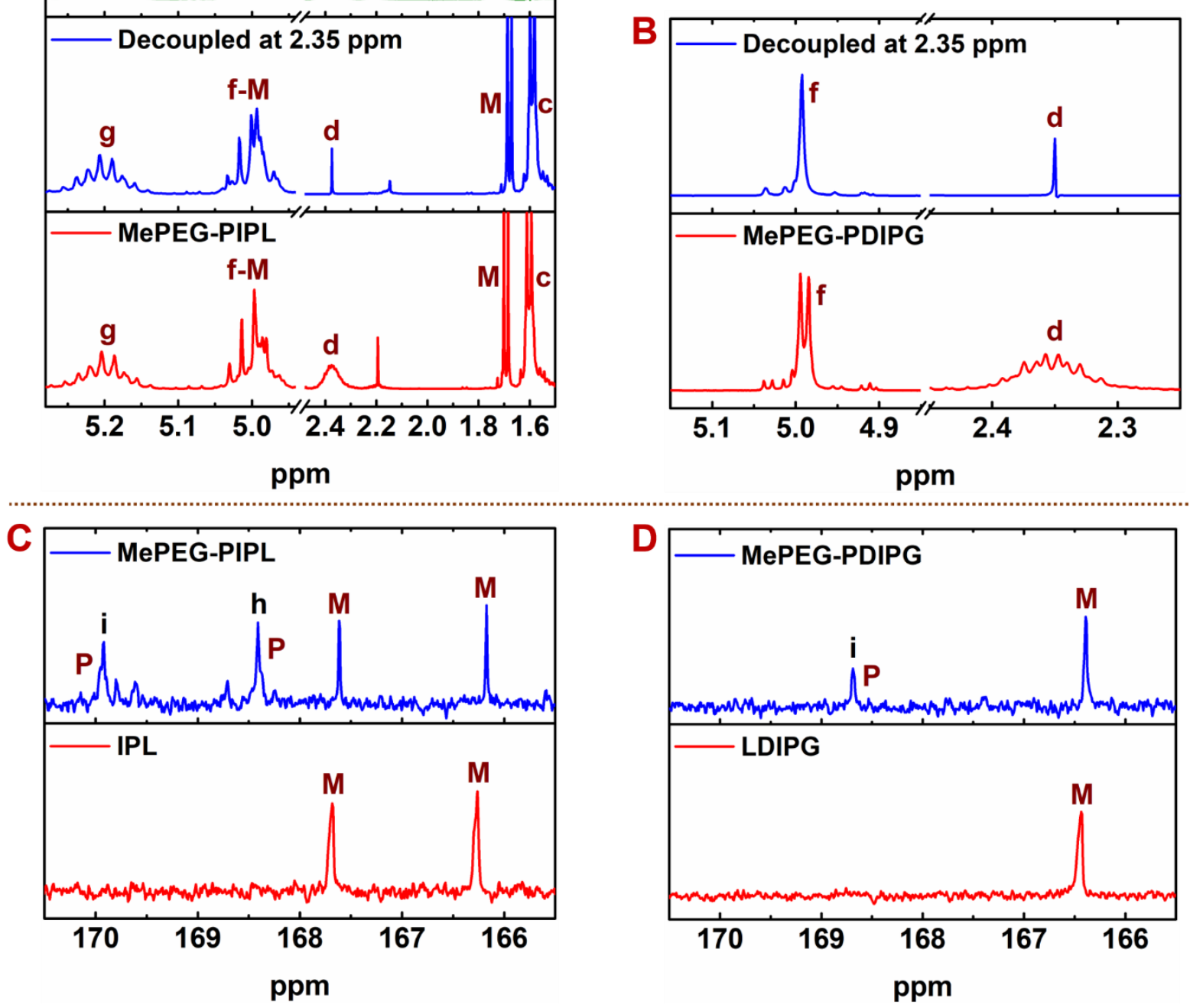

Figure S36. Normal and homonuclear decoupled ${ }^{1} \mathrm{H}$ NMR spectra $\left(\mathrm{CDCl}_{3}, 400 \mathrm{MHz}\right)$ of MePEG-PIPL (A), MePEG-PDIPG (B) and ${ }^{13} \mathrm{C}$ NMR spectra of MePEG-PIPL (C), MePEG-PDIPG (D). M: Monomer, P: Polymer 


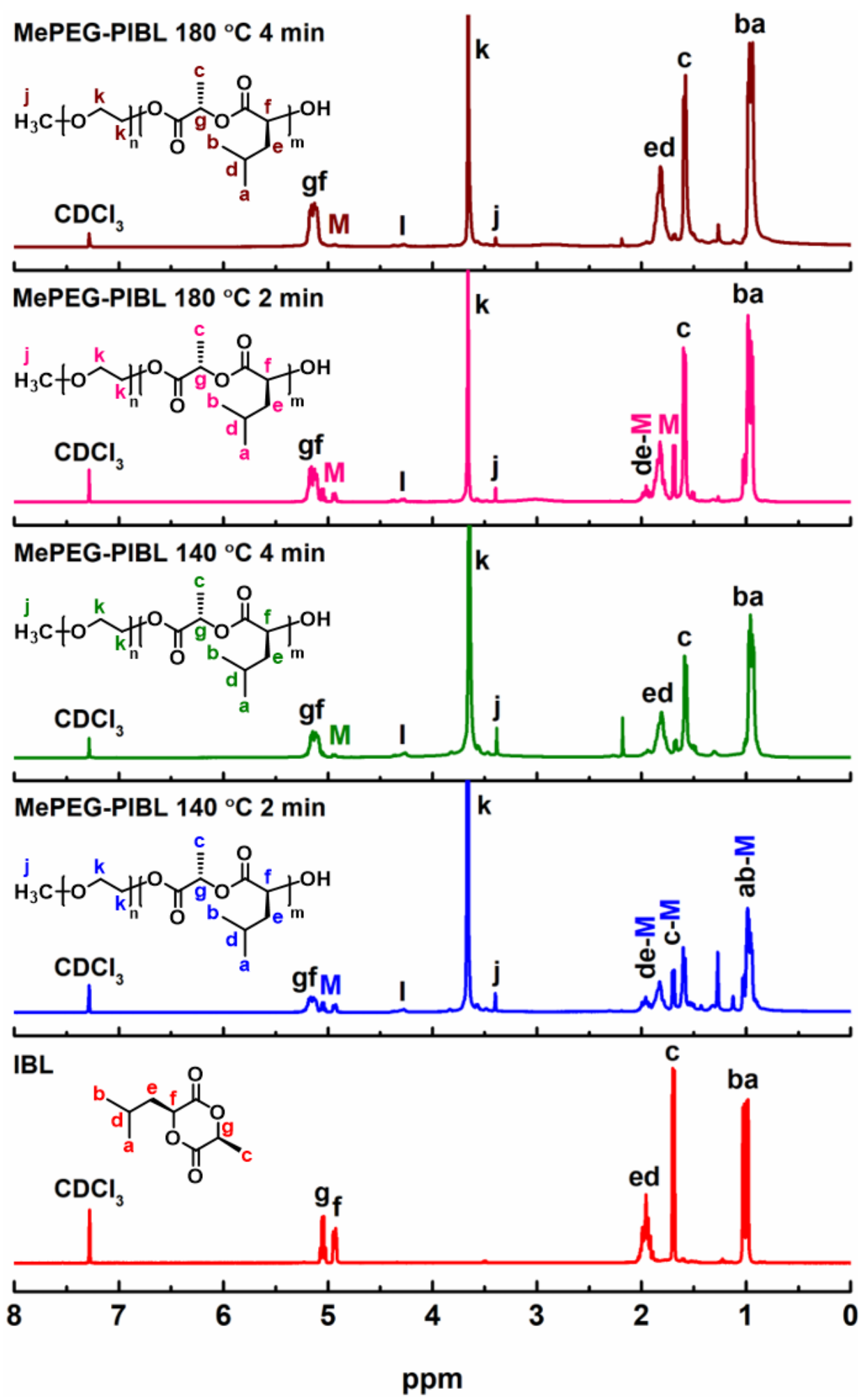

Figure S37. ${ }^{1} \mathrm{H}$ NMR spectra of IBL and MePEG-PIBL copolymers in melt polymerization during different reaction times and temperatures. 


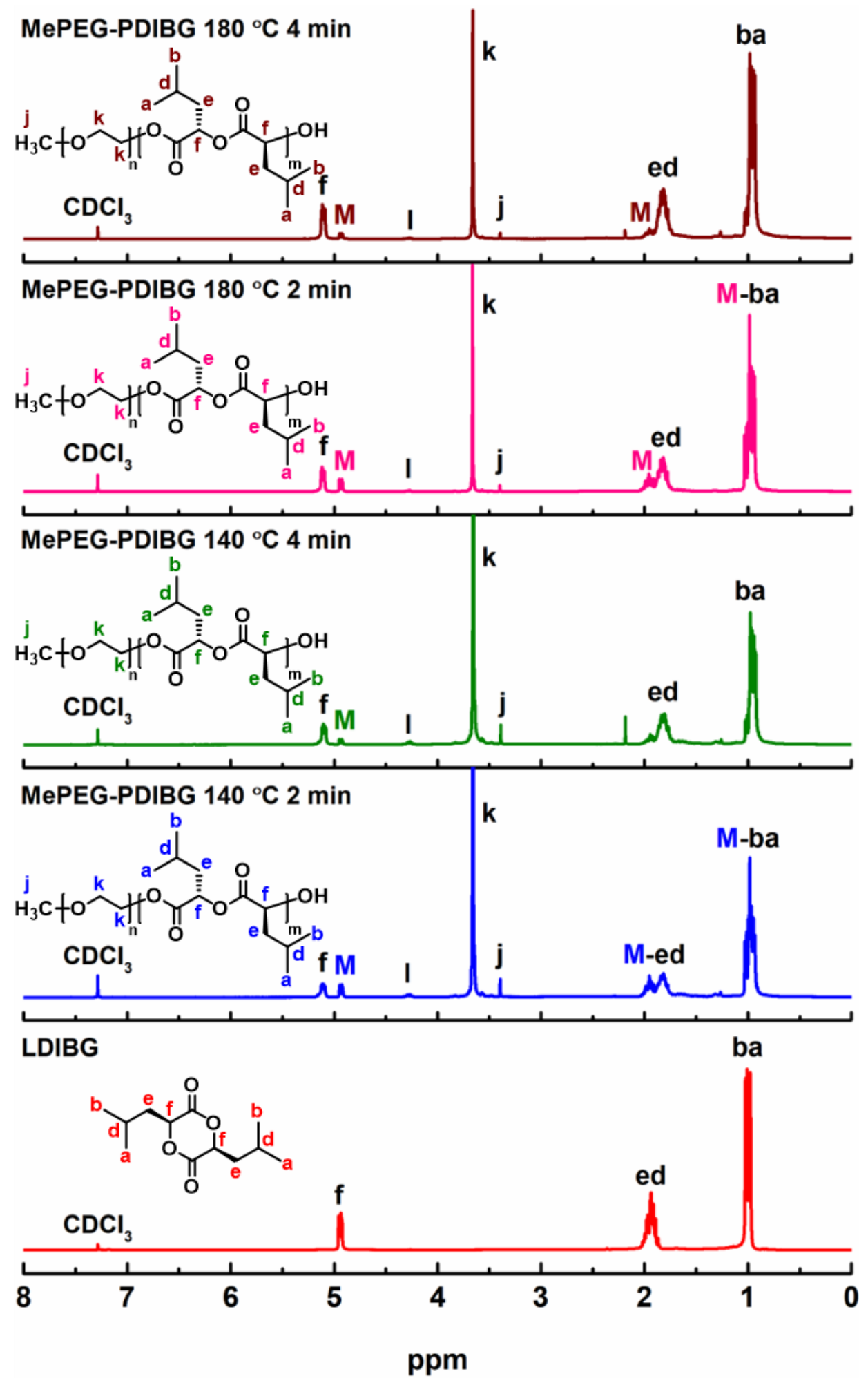

Figure S38. ${ }^{1} \mathrm{H}$ NMR spectra of LDIBG and MePEG-PDIBG copolymers in melt polymerization during different reaction times and temperatures. 


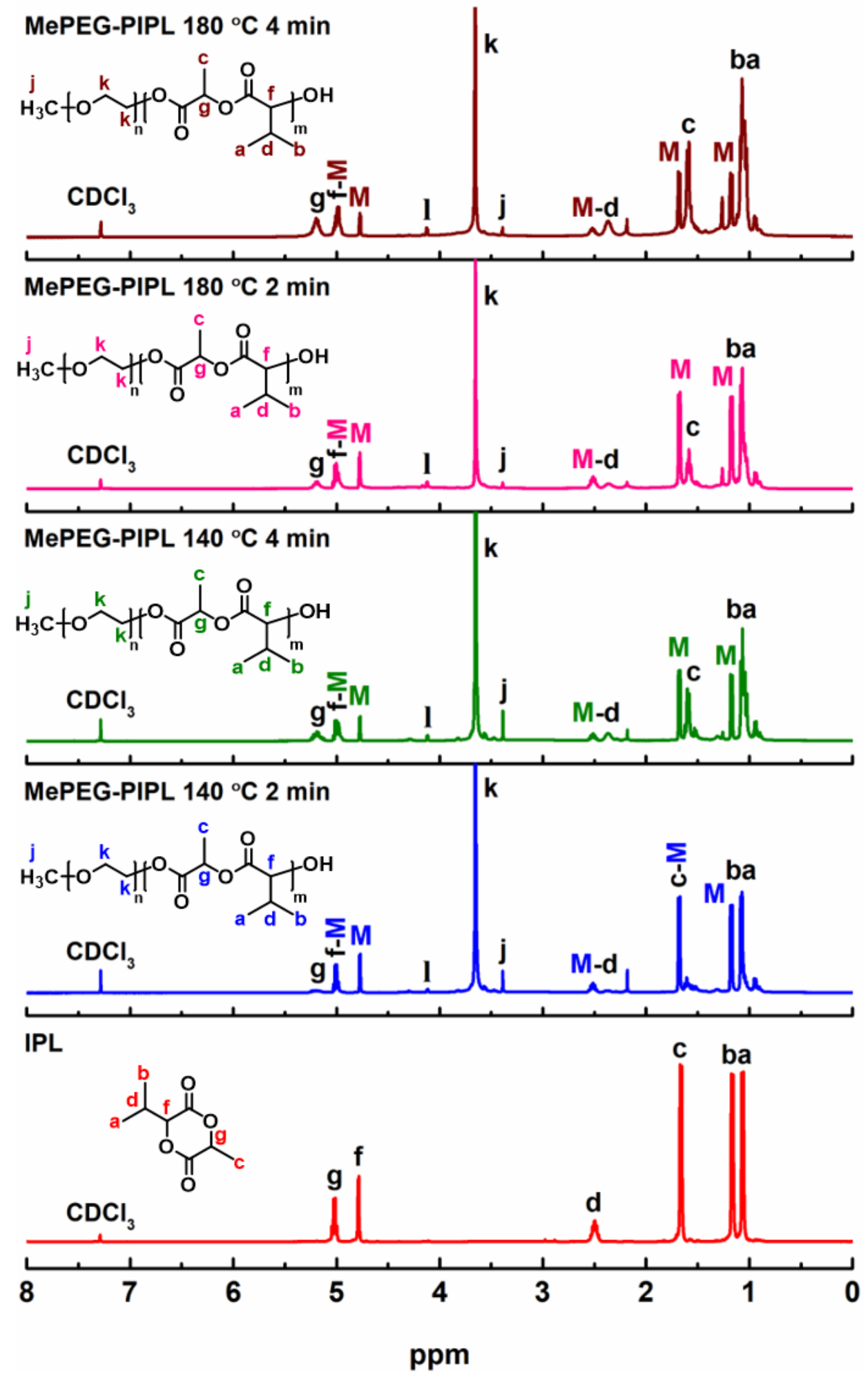

Figure S39. ${ }^{1} \mathrm{H}$ NMR spectra of IPL and MePEG-PIPL copolymers in melt polymerization during different reaction times and temperatures. 


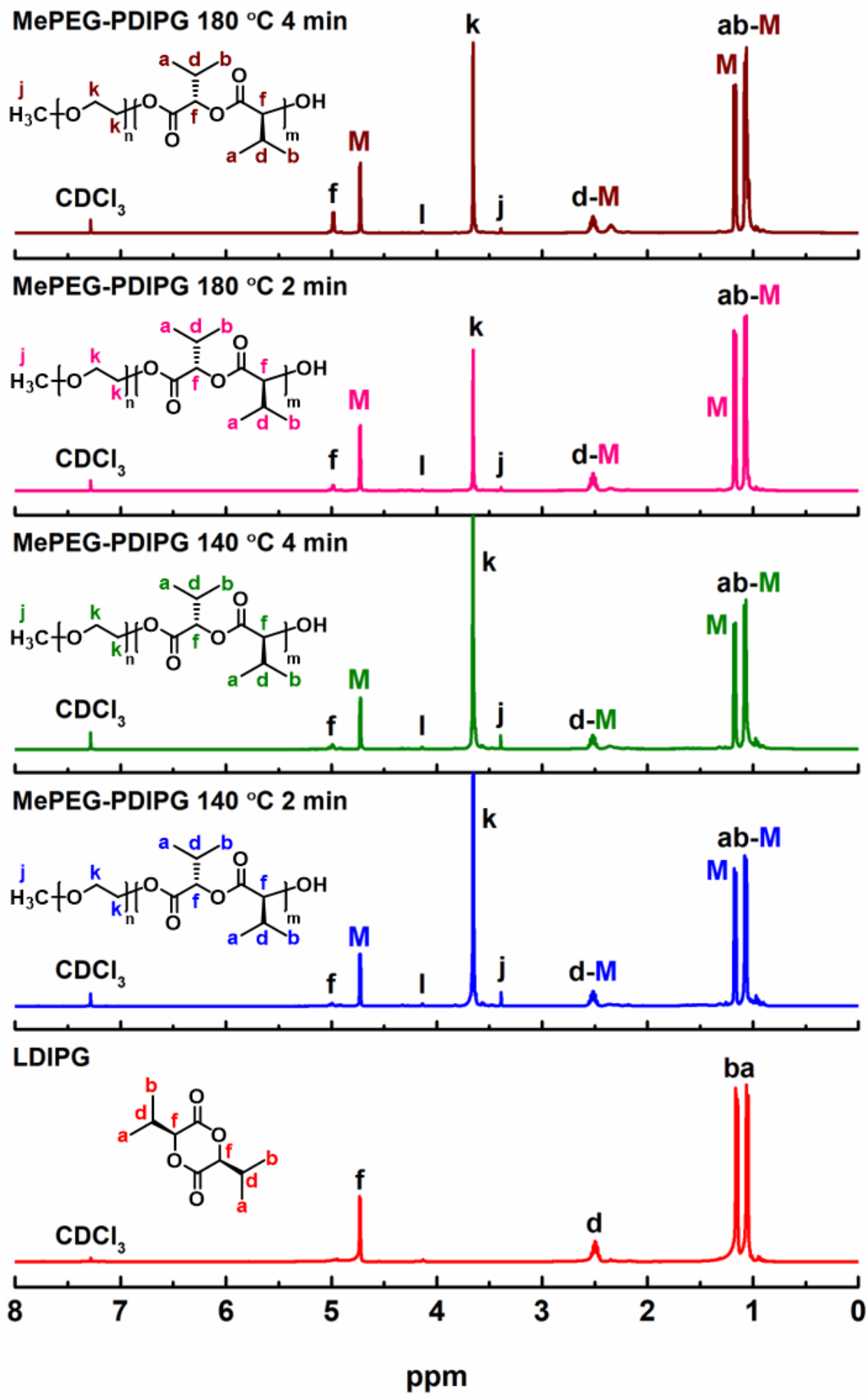

Figure S40. ${ }^{1} \mathrm{H}$ NMR spectra of LDIPG and MePEG-PDIPG copolymers in melt polymerization during different reaction times and temperatures. 

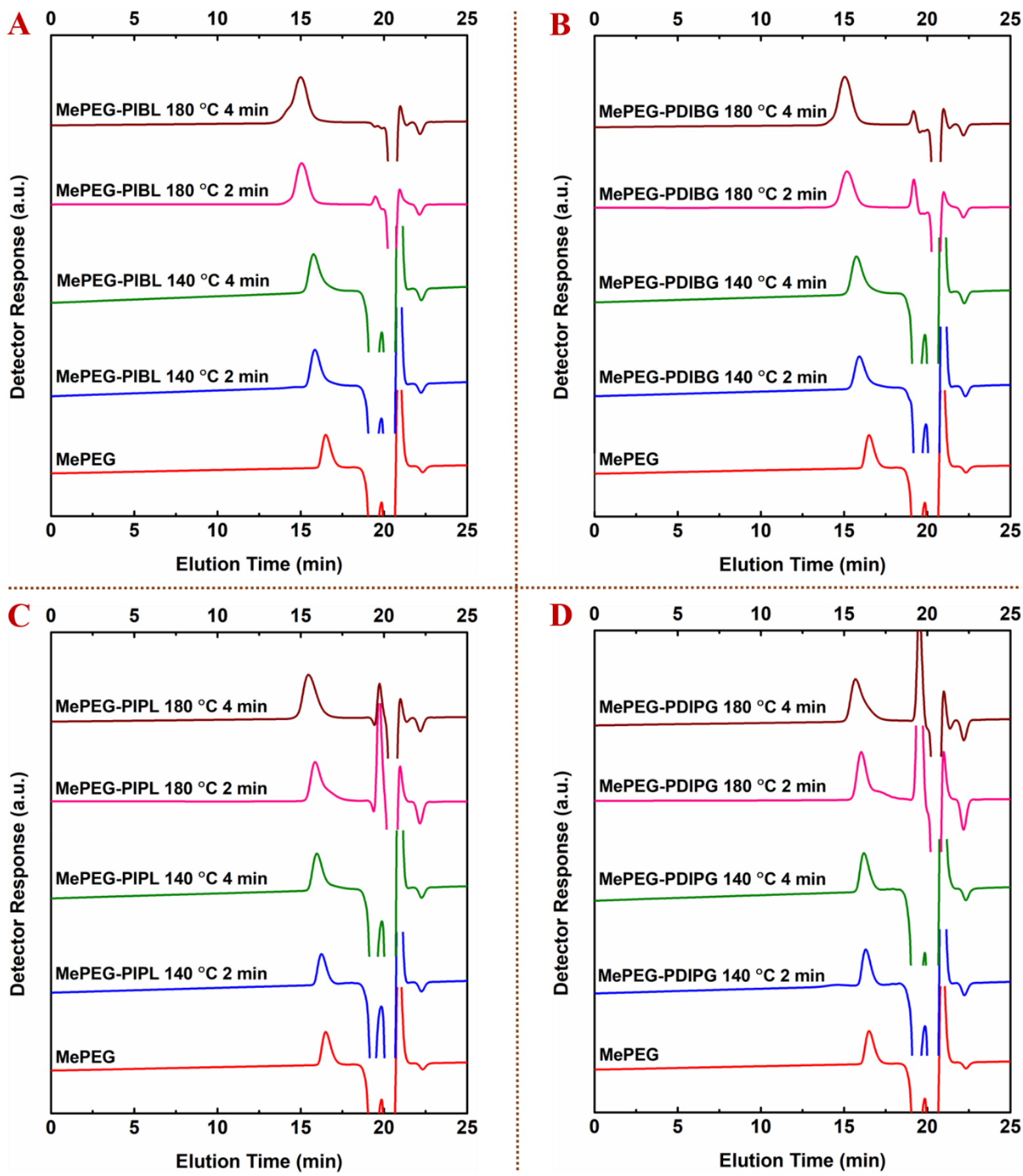

Figure S41. GPC curves of MePEG and MePEG-PIBL copolymers (A), MePEG-PDIBG copolymers (B), MePEG-PIPL copolymers (C), and MePEG-PDIPG copolymers (D) in melt polymerization during different reaction times and temperatures. 


\section{Live/Dead Staining Assay}

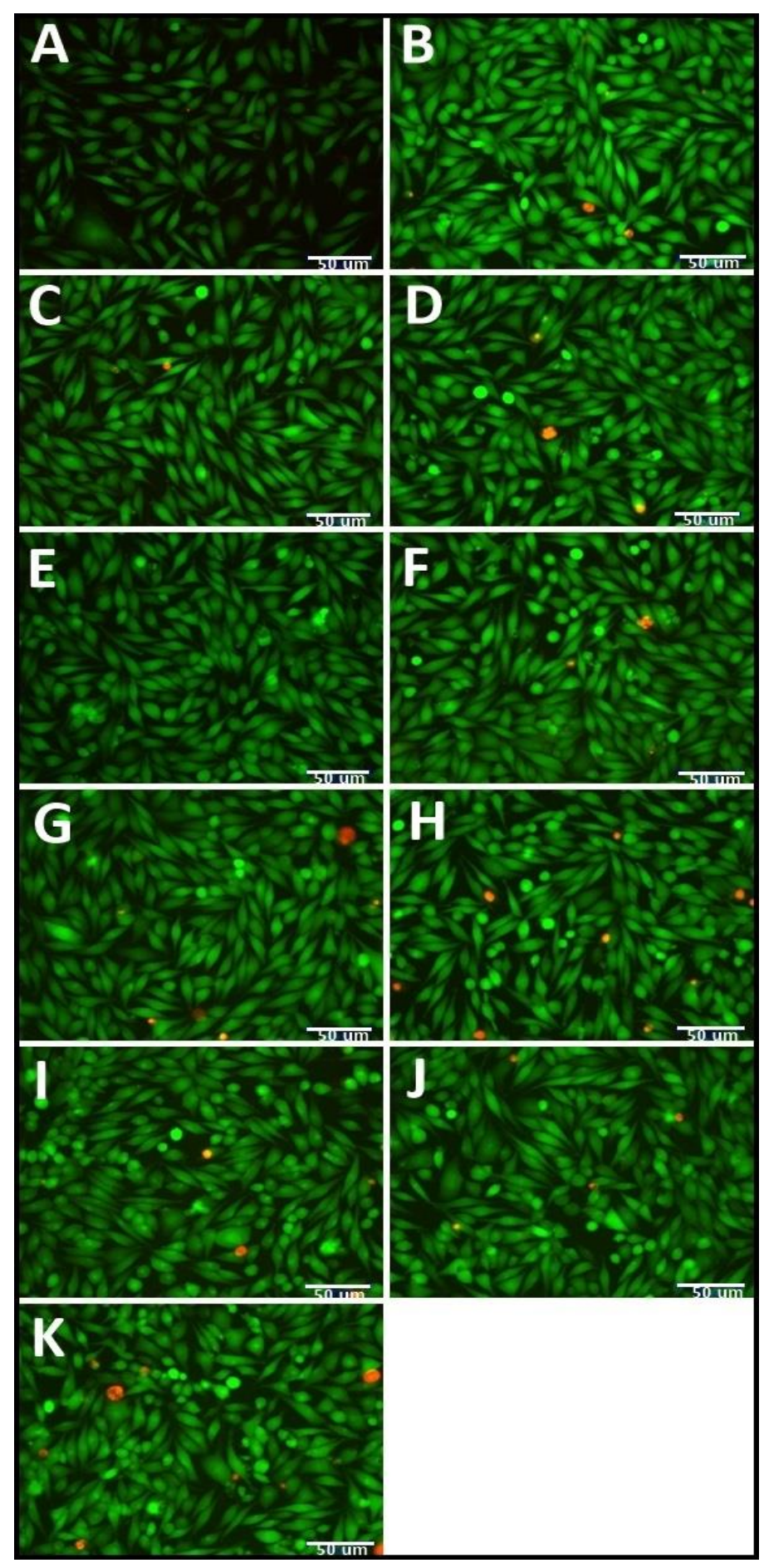

Figure S42. Fluorescence micrographs of L929 cells cultured with different concentrations of MePEG-PIBL diblock copolymer 8 in culture medium for $48 \mathrm{~h}$ and subsequently stained with calcein-AM and ethidium homodimer (live/dead staining). Live cells were stained by calcein $\mathrm{AM}$, producing an intense green fluorescence; dead cells were stained by ethidium homodimer, producing red fluorescence of nucleic acids. A: TCP, B: $0.1 \mathrm{mg} / \mathrm{mL}, C: 0.2 \mathrm{mg} / \mathrm{mL}$, D: $0.4 \mathrm{mg} / \mathrm{mL}, \mathrm{E}: 0.6 \mathrm{mg} / \mathrm{mL}, \mathrm{F}: 0.8 \mathrm{mg} / \mathrm{mL}, \mathrm{G}: 1.0 \mathrm{mg} / \mathrm{mL}, \mathrm{H}: 1.5 \mathrm{mg} / \mathrm{mL}, \mathrm{I}: 2.0 \mathrm{mg} / \mathrm{mL}, \mathrm{J}: 2.5$ $\mathrm{mg} / \mathrm{mL}, \mathrm{K}: 3.0 \mathrm{mg} / \mathrm{mL}$. 


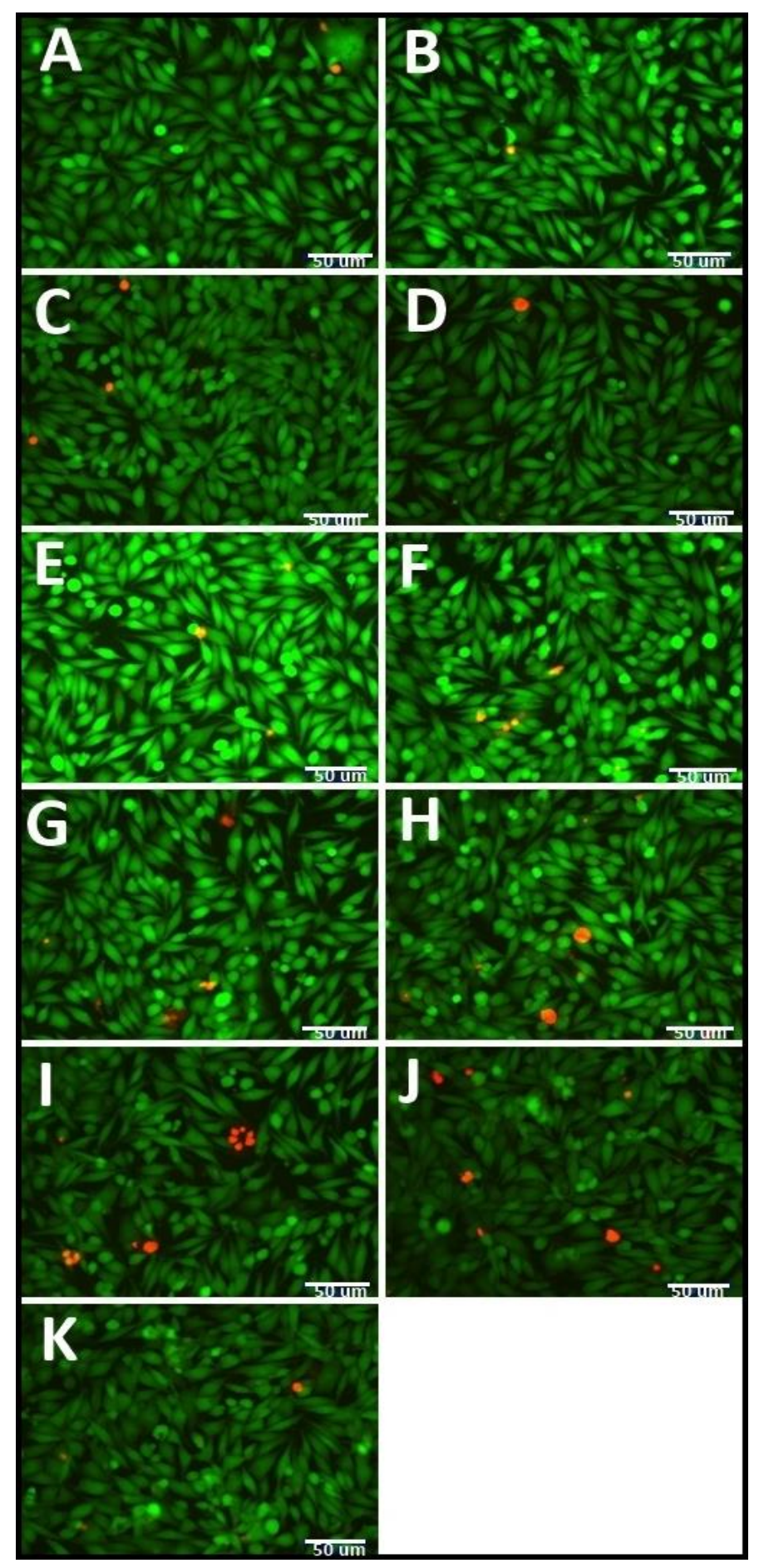

Figure S43. Fluorescence micrographs of L929 cells cultured with different concentrations of PIBL-PEG-PIBL triblock copolymer 11 in culture medium for $48 \mathrm{~h}$ and subsequently stained with calcein-AM and ethidium homodimer (live/dead staining). Live cells were stained by calcein-AM, producing an intense green fluorescence; dead cells were stained by ethidium homodimer, producing red fluorescence of nucleic acids. A: TCP, B: $0.1 \mathrm{mg} / \mathrm{mL}, \mathrm{C}: 0.2 \mathrm{mg} / \mathrm{mL}$, D: $0.4 \mathrm{mg} / \mathrm{mL}, \mathrm{E}: 0.6 \mathrm{mg} / \mathrm{mL}, \mathrm{F}: 0.8 \mathrm{mg} / \mathrm{mL}, \mathrm{G}: 1.0 \mathrm{mg} / \mathrm{mL}, \mathrm{H}: 1.5 \mathrm{mg} / \mathrm{mL}, \mathrm{I}: 2.0 \mathrm{mg} / \mathrm{mL}, \mathrm{J}: 2.5$ $\mathrm{mg} / \mathrm{mL}, \mathrm{K}: 3.0 \mathrm{mg} / \mathrm{mL}$. 


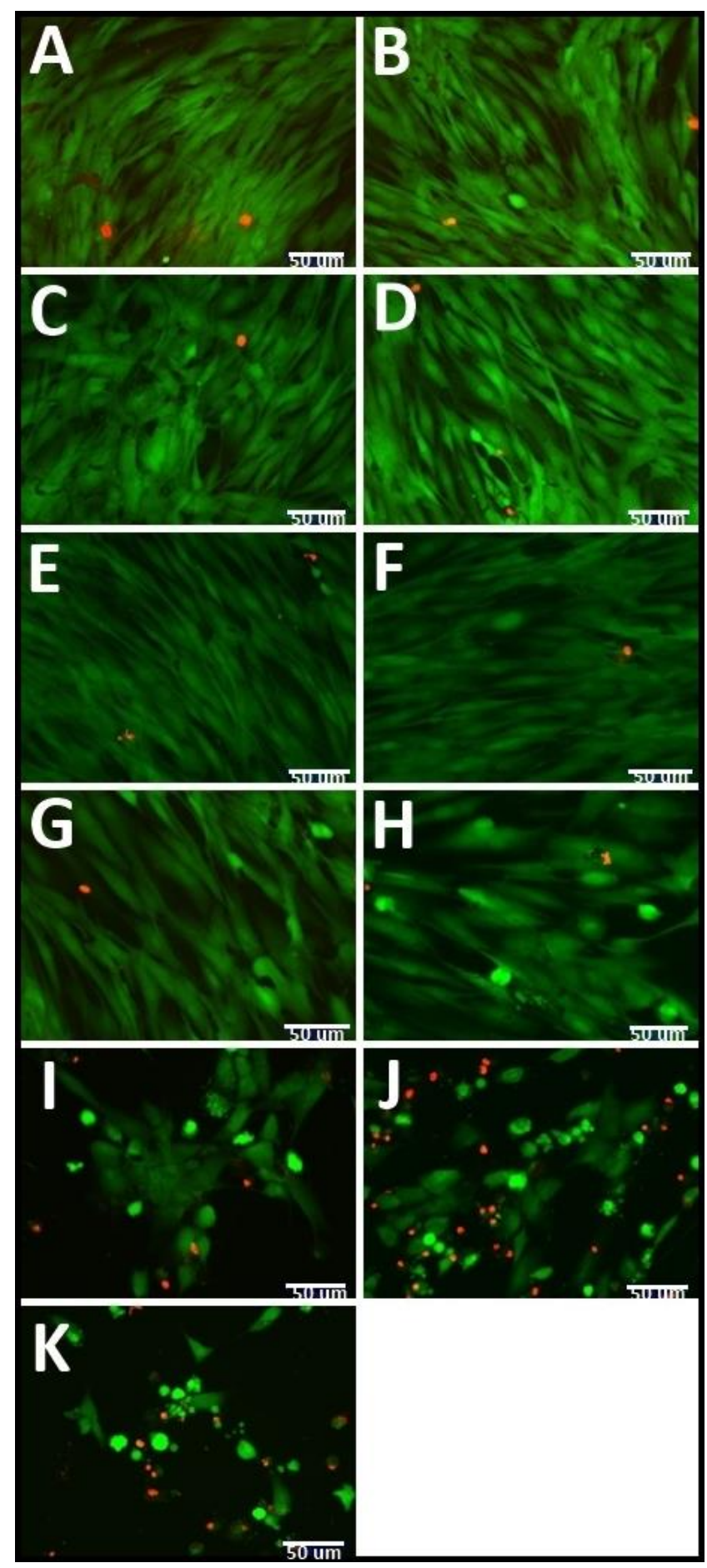

Figure S44. Fluorescence micrographs of human primary fibroblasts cultured with different concentrations of MePEG-PIBL diblock copolymer 8 in culture medium for $48 \mathrm{~h}$ and subsequently stained with calcein-AM and ethidium homodimer (live/dead staining). Live cells were stained by calcein-AM, producing an intense green fluorescence; dead cells were stained by ethidium homodimer, producing red fluorescence of nucleic acids. A: TCP, B: $0.1 \mathrm{mg} / \mathrm{mL}$, C: $0.2 \mathrm{mg} / \mathrm{mL}, \mathrm{D}: 0.4 \mathrm{mg} / \mathrm{mL}, \mathrm{E}: 0.6 \mathrm{mg} / \mathrm{mL}, \mathrm{F}: 0.8 \mathrm{mg} / \mathrm{mL}, \mathrm{G}: 1.0 \mathrm{mg} / \mathrm{mL}, \mathrm{H}: 1.5 \mathrm{mg} / \mathrm{mL}, \mathrm{I}: 2.0$ $\mathrm{mg} / \mathrm{mL}, \mathrm{J}: 2.5 \mathrm{mg} / \mathrm{mL}, \mathrm{K}: 3.0 \mathrm{mg} / \mathrm{mL}$. 


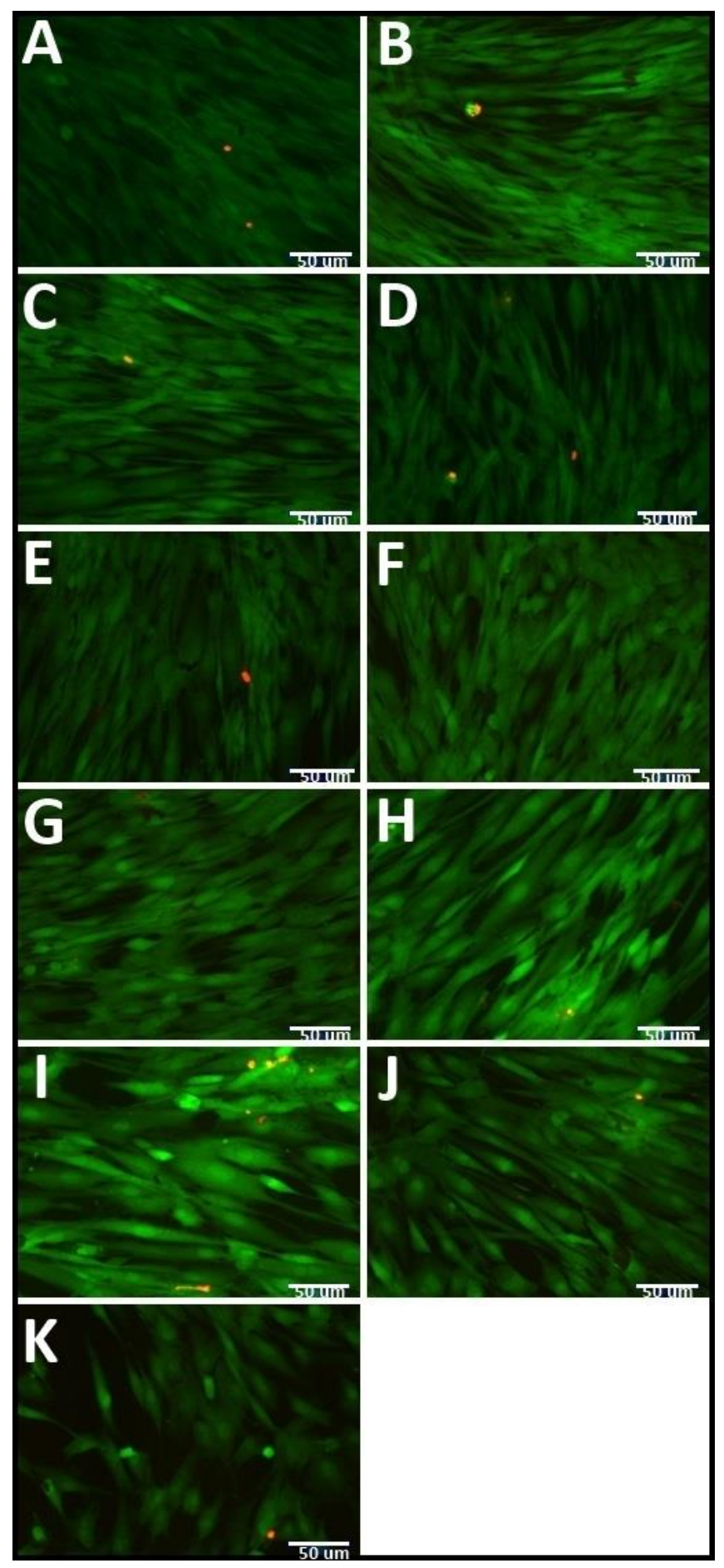

Figure S45. Fluorescence micrographs of human primary fibroblasts cultured with different concentrations of PIBL-PEG-PIBL triblock copolymer 11 in culture medium for $48 \mathrm{~h}$ and subsequently stained with calcein-AM and ethidium homodimer (live/dead staining). Live cells were stained by calcein-AM, producing an intense green fluorescence; dead cells were stained by ethidium homodimer, producing red fluorescence of nucleic acids. A: TCP, B: $0.1 \mathrm{mg} / \mathrm{mL}$, C: $0.2 \mathrm{mg} / \mathrm{mL}, \mathrm{D}: 0.4 \mathrm{mg} / \mathrm{mL}, \mathrm{E}: 0.6 \mathrm{mg} / \mathrm{mL}, \mathrm{F}: 0.8 \mathrm{mg} / \mathrm{mL}, \mathrm{G}: 1.0 \mathrm{mg} / \mathrm{mL}, \mathrm{H}: 1.5 \mathrm{mg} / \mathrm{mL}$, I: 2.0 $\mathrm{mg} / \mathrm{mL}, \mathrm{J}: 2.5 \mathrm{mg} / \mathrm{mL}, \mathrm{K}: 3.0 \mathrm{mg} / \mathrm{mL}$. 